University of Arkansas, Fayetteville

ScholarWorks@UARK

10-1-2005

\title{
Parent and Student Voices on the First Year of the DC Opportunity Scholarship Program
}

Thomas Stewart

University of Arkansas, Fayetteville

Patrick J. Wolf

University of Arkansas, Fayetteville, pwolf@uark.edu

Stephen Q. Cornman

Georgetown University

Follow this and additional works at: https://scholarworks.uark.edu/scdp

Part of the Education Policy Commons, Public Policy Commons, and the Social Policy Commons

\section{Citation}

Stewart, T., Wolf, P. J., \& Cornman, S. Q. (2005). Parent and Student Voices on the First Year of the DC Opportunity Scholarship Program. School Choice Demonstration Project. Retrieved from https://scholarworks.uark.edu/scdp/23

This Report is brought to you for free and open access by the Education Reform at ScholarWorks@UARK. It has been accepted for inclusion in School Choice Demonstration Project by an authorized administrator of ScholarWorks@UARK. For more information, please contact scholar@uark.edu. 


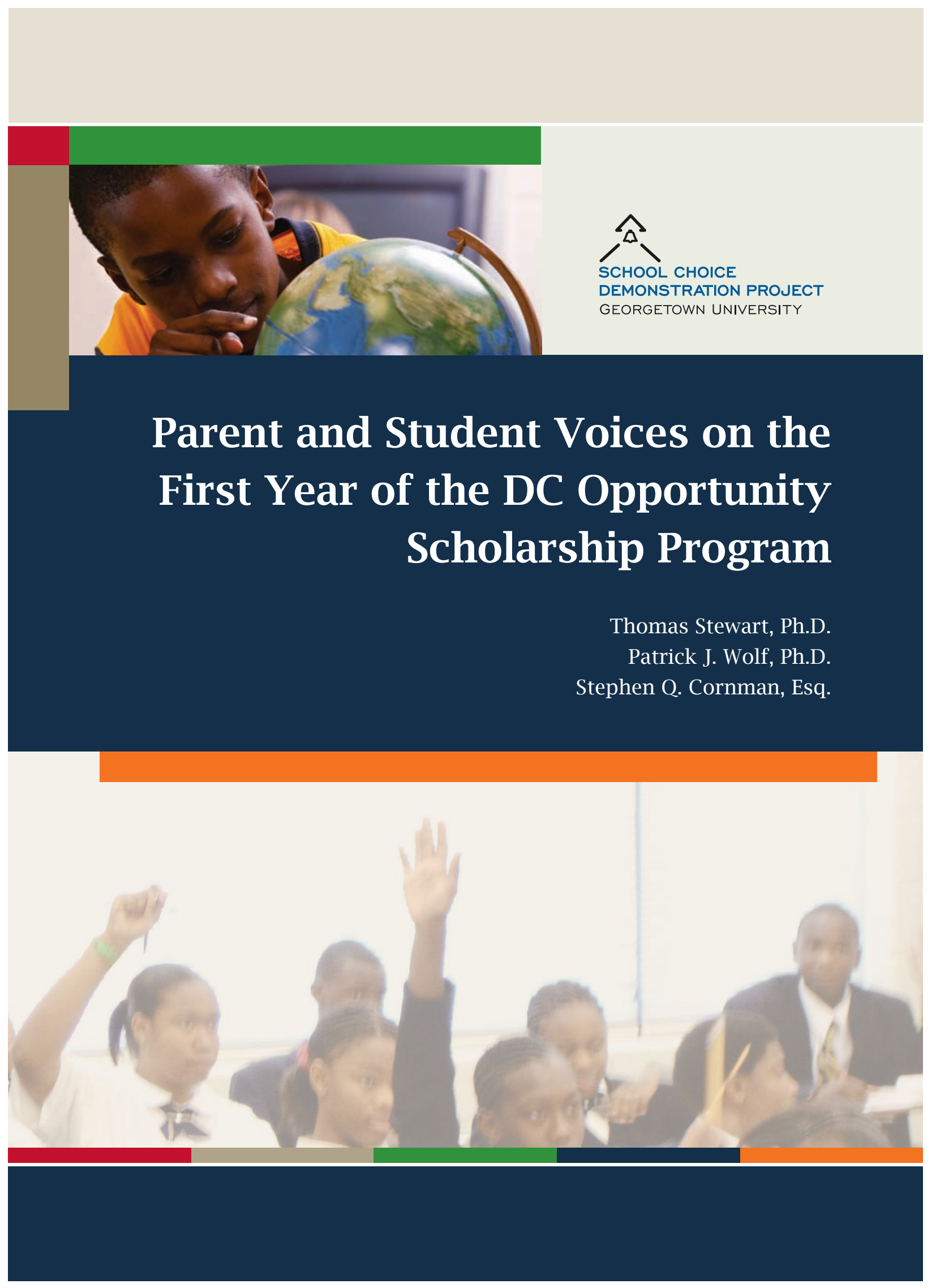




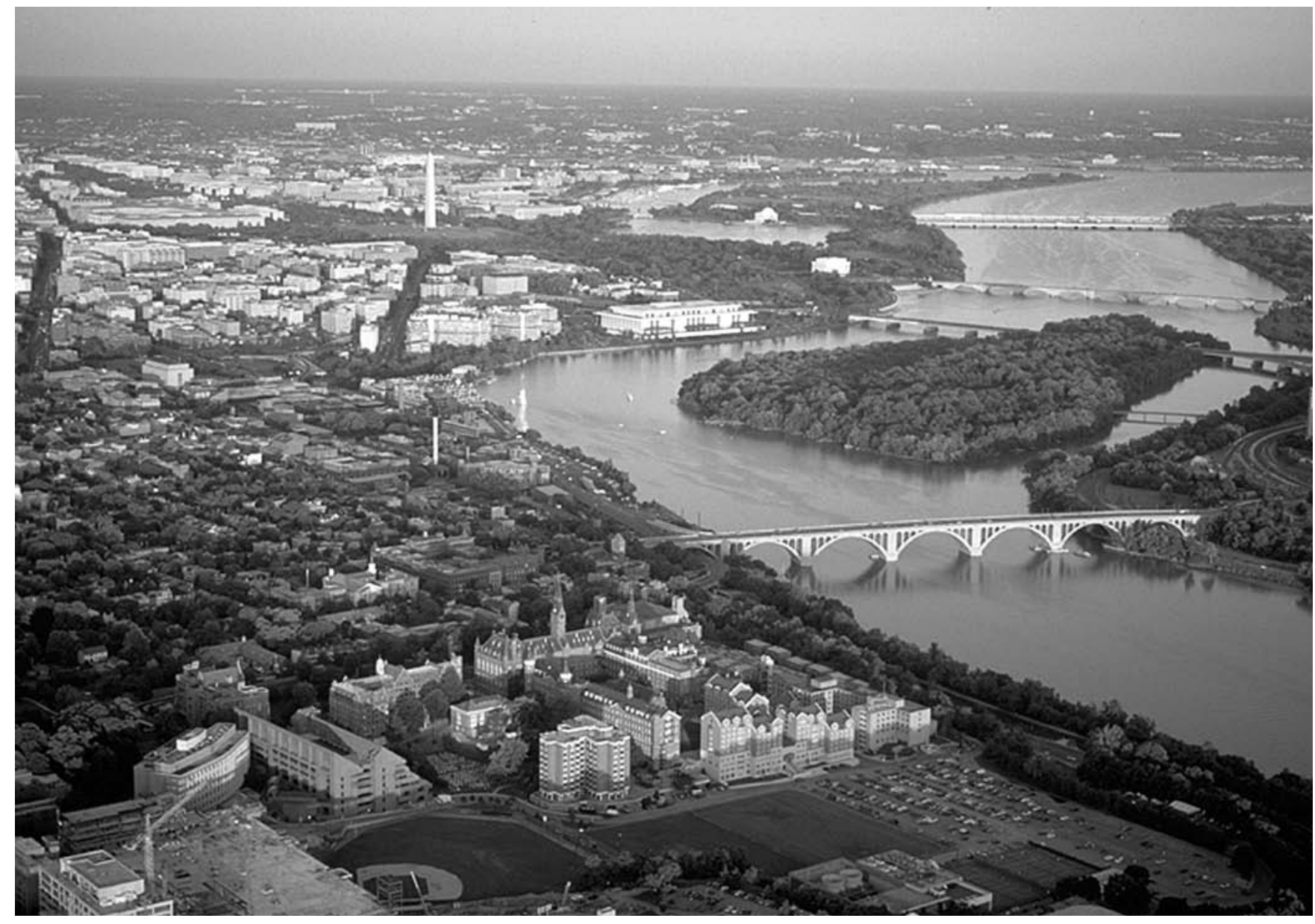

\section{GEORGETOWN UNIVERSITY SCHOOL CHOICE DEMONSTRATION PROJECT}

The Georgetown University School Choice Demonstration Project (SCDP), based within the Georgetown Public Policy Institute (GPPI), is an education research center devoted to the non-partisan study of the effects of school choice policy and is staffed by leading school choice researchers and scholars.

SCDP's national team of researchers, institutional research partners and staff are devoted to the rigorous evaluation of school choice programs and other school improvement efforts across the country. SCDP is committed to raising and advancing the public's understanding of the strengths and limitations of school choice policies and programs by conducting comprehensive research on what happens to students, families, schools and communities when more parents are allowed to choose their child's school.

Led by Dr. Patrick J. Wolf, Associate Professor of Public Policy, SCDP is playing a central role in efforts to evaluate the country's first federally sponsored K-12 scholarship initiative: The DC Opportunity Scholarship Program. In partnership with Westat and Chesapeake Research Associates, SCDP is conducting the official evaluation of the Program's impact using a Randomized Control Trial research design. With support from private foundations, SCDP also is conducting mixed-method investigations into the possible competitive effects of the Opportunity Scholarship Program on the performance of public schools, the behavioral response of educators to the program, its effects on private school capacity and school integration, and how parents and students are experiencing this important new federal education initiative. 


\section{Parent and Student Voices on the First Year of the DC \\ Opportunity Scholarship Program}

Thomas Stewart, Ph.D.

Patrick J. Wolf, Ph.D.

Stephen Q. Cornman, Esq.

October 2005

SCDP Report 05-01

Georgetown University Public Policy Institute

School Choice Demonstration Project

Box 571444

3300 Whitehaven Avenue, NW, Suite 5000

Washington, DC 20007

202-687-6323 



\section{ACKNOWLEDGEMENTS}

The authors gratefully acknowledge the valuable assistance of the following project contributors:

- Darnita Akers

- David Banks, Ph.D.

- Jessica Boccardo

- Donald Brown

- Marlo Crandall

- Daniel Hoople

- Rachel Greszler

- Elizabeth Rutzick

- Benjamin Traster

- Ashley Zollinger

We also benefited immensely from the comments of Howard Fuller, Laura Hamilton, Jeffrey Henig, and Mark Schneider on an earlier draft of this report. Nevertheless, the claims made and any remaining shortcomings in this report remain the sole responsibility of the authors.

This research was funded by the Annie E. Casey Foundation through a grant to Georgetown University. We thank them for their support but acknowledge that the findings and conclusions presented in this report are those of the authors alone, and do not necessarily reflect the opinions of the Foundation or the University.

Finally, we are extremely grateful for the voluntary participation of the Parent and Student Voices families, school administrators, and staff of the Washington Scholarship Fund for cooperating with this study. Consistent with our promise to participants, their names will remain confidential. 


\section{EXECUTIVE SUMMARY}

In the 50 years since economist Milton Friedman published "The Role of Government in Education"1 scholars and policy makers have been debating how parental choice through market mechanisms can and does operate in education. Market "optimists" argue that education is a service that can be produced under a variety of arrangements and that parents are natural education consumers. ${ }^{2}$ Market "pessimists" argue that education is a public good that should be produced in government-run schools, and that school choice programs suffer "market failure" because only advantaged families will have the resources and experience to choose effectively. ${ }^{3}$

\section{The Opportunity Scholarship Program and Parent and Student Voices Study}

On January 23, 2004, President Bush signed the DC School Choice Incentive Act into law. ${ }^{4}$ This landmark piece of legislation included $\$ 14$ million in funding for what would come to be called the DC Opportunity Scholarship Program (OSP). The OSP is the first federally funded $\mathrm{K}-12$ scholarship program in the country and is designed to provide approximately 1,700 lowincome DC children with tuition scholarships worth up to $\$ 7,500$ to cover the costs of attending participating K-12 nonpublic schools in the District. The pilot program is authorized to operate for five years and is being implemented by a group of non-profit organizations headed by the Washington Scholarship Fund (WSF).

In addition to extending educational choices to an economically disadvantaged group of DC families, the OSP also provides the opportunity to learn more about what happens when more families have the opportunity and responsibility to choose a private school for their children. The U.S. Department of Education, through the Institute for Education Sciences, has contracted for the conduct of a rigorous experimental evaluation of the impact of the Program on a number of student outcomes including student achievement. Here we provide information from a separate, independent, qualitative assessment of how families are experiencing the Program, including why they are seeking choice, how they are selecting schools, what challenges they are facing, and how parents, students, schools, and the OSP are working to try to realize the goals of the Program. Included in the report is information about what seems to be working well, what problems have been encountered along the way, and recommendations from parents and students regarding how the Program can better serve their needs.

The information presented in this report was gleaned from 12 focus groups conducted in the fall of 2004 and the spring of 2005 with the parents and older students of 45 families participating in the OSP who volunteered to participate. Although the participating families are

\footnotetext{
${ }^{1}$ Milton Friedman, "The Role of Government in Education," in Robert Solo (ed.), Economics and the Public Interest (Rutgers, NJ: Rutgers University Press, 1955).

${ }^{2}$ See Milton Friedman, Capitalism and Freedom (Chicago: University of Chicago Press, 1962); John E. Chubb and Terry M. Moe. Politics, Markets, and America's Schools (Washington: Brookings, 1990).

${ }^{3}$ See John Dewey, Democracy and Education (New York: Macmillan, 1916); Amy Gutmann, Democratic Education (Princeton, NJ: Princeton University Press, 1987); Helen F. Ladd, Market-Based Reforms in Urban Education (Washington, DC: Economic Policy Institute, 2002); Henry L. Levin, "Educational Vouchers: Effectiveness, Choice, and Costs," Journal of Policy Analysis and Management, 17 (June 1998).

${ }^{4}$ Title III of the District of Columbia Appropriations Act of 2004, Division C of HR 2673, 118 Stat. 117, DC Code Sec. 38-1851.01.
} 
broadly representative of the Program's client population, they are likely to be somewhat more highly motivated than typical OSP families due to their willingness to take extra time to share their experiences with us. Thus, readers should exercise caution in drawing firm conclusions about the OSP as a whole based merely upon the collective experiences of these 45 self-selected families.

Although this study is not, and cannot be, a rigorous impact evaluation of the Program, it does chronicle the experience of a large and diverse group of OSP families during the fast-paced initial implementation of the pilot program. The report allows participating parents and students to speak freely and extensively to policy makers, implementers, researchers, and the broader public about what is happening in their lives as a result of enrolling in this new school choice initiative.

The voices of OSP parents and students tell a complex story of hope, opportunity, challenge, effort, occasional frustration, and general satisfaction. The participants themselves expressed how important they think it is that interested stakeholders hear and understand the story of their experiences in this new and ambitious educational program.

\section{Specific Findings from the First Year}

Most of the material in the main body of the report consists of actual quotes from parents and students regarding matters that are central to the theoretical and policy debates surrounding school choice. A representative selection of participant quotes is available in the summary document that accompanies this more comprehensive report. ${ }^{5}$ For this executive summary, we simply provide our own overview of the pattern of responses that we encountered while analyzing the qualitative focus group data. The summary is presented in the order in which the material appears in the comprehensive report that follows.

\section{A. Parent and Student Voices on Their Introduction to Choice}

The role of parents as consumers of educational options is an essential feature of the school choice debate. Prior to the creation of the OSP, the vast majority of families in this study had not explored educational opportunities beyond the traditional public school their children were formally assigned. This suggests that most of them had limited experience exercising the consumer behavior implicit in school choice. However, once these families learned about the OSP, particularly the schools that were involved, they became immediately excited about the opportunity. They consistently expressed gratitude for the financial support that allowed them choice amongst a variety of schools beyond the limited options they had previously experienced prior to the OSP.

\footnotetext{
${ }^{5}$ Thomas Stewart, Patrick J. Wolf, and Stephen Q. Cornman, Parent and Student Voices on the First Year of the DC Opportunity Scholarship Program, Report of the School Choice Demonstration Project, Georgetown University, Washington DC, October 2005, SCDP 05-01 SUM. The summary report is available for download in text or audio format and in English or Spanish at www.georgetown.edu/research/scdp.
} 


\section{B. Parent and Student Voices on What Motivates Families to Participate}

The popular literature strongly suggests that parents who seek choice are primarily motivated by a desire to provide their children with the best education possible. Generally speaking, the families in this study were driven by such a desire. When challenged to provide more detailed information about the sources of their motivation, their responses suggested that the OSP was an extremely rare opportunity and they were prepared to overcome any real or perceived obstacles to seize it. Rather than citing the limitations of their prior educational experiences as a source of motivation, most cited reasons that suggested they were seeking a better opportunity. These reasons will be discussed in greater detail below.

\section{Parent and Student Voices on What Families Look for in Schools}

Parents cited a variety of reasons for selecting schools under the auspices of the OSP. The most common considerations to which parents pointed to were school safety and a religious or values-based educational environment. In addition, parents were seeking a more rigorous academic curriculum, smaller classes, the opportunity to learn foreign languages, and private schools in close proximity to their home.

\section{Parent and Student Voices on the Importance of Information}

During the focus group discussions, accurate and timely information about the Program and the participating schools emerged as an important point of discussion. The most discussed sources of information for OSP parents included WSF guides, participating schools, friends, and other scholarship families. Most parents expressed satisfaction with the quality and quantity of information provided by WSF, although they generally agreed with the notion that "more is better." Those who attended the school fair and/or visited schools felt they were better equipped to make an informed choice. Several parents, however, shared fears that what parents see during the school visits might not be what they get and suggested that an accountability process be instituted to minimize "surprises" once schools have been selected.

\section{E. Parent and Student Voices on How Families Choose Schools}

Evidence from existing research suggests that choice works best when: (1) parents have a range of high quality options to choose from; and (2) when their children, particularly middle and high school ages, are actively involved in the decision making process. The options available to OSP families varied significantly based on the grade level of the student, with the choices significantly restricted at the high school level. In addition, families participating in the OSP had to factor the lottery into their decision-making. Several parents noted that they did not inform their children about the OSP until after they knew definitively that they had been selected in the lottery. In most cases, though the parents remembered being very excited about the prospects of winning the lottery, they were reluctant to engage their children for fear that losing the lottery would be a major source of disappointment for the family. 


\section{F. Parent and Student Voices on the New School Environment}

Parents and students paint a complex picture of their new private schools. Some students complained of poorly maintained facilities. Both students and parents generally reported more challenging schoolwork that is pushing the students to the limits of their abilities. They report stricter discipline, which they generally applaud. The families spoke of great variation in both the type and amount of extracurricular activities offered at their new private schools.

\section{G. Parent Voices on Responses to New Challenges}

Considering the potential differences between public and private schools, it is no surprise that OSP parents faced adjustment challenges in the Program's inaugural year. Dialogue from the parent focus groups upheld many of the observations cited in the school choice literature. Most OSP parents, for example, became more active in their child's education both at home and in the schools their child attends. While some found the greater time commitment to be a challenge, most seemed prepared for the increased demand. In response to higher academic standards and increased student workloads, parents usually adjusted their behavior, though at times they felt that the schools needed to be more accommodating of their schedules. Additionally, parents desired a network of OSP parents with whom they could exchange experiences and seek support, apart from the school-based parental organizations already in existence. The WSF has established just such an organization in response to the demands of its clients.

\section{H. Parent and Student Voices on Student-School Responses to New Challenges}

Students identified a slight to distinct difference in the learning environment in their new schools. Facilities, extracurricular activities, disciplinary standards, school culture and levels of receptivity were among the most frequently mentioned differences. Most of the parents and students acknowledged that the private schools practiced stricter discipline standards than their children's previous schools. In several cases, parents observed a notable improvement in their children's behavior due to the higher level of discipline. Parents and students expressed mixed responses concerning the receptiveness of private schools to OSP recipients and their families. Some parents and students felt the schools welcomed them, while others shared instances where they felt they were singled out or were treated differently. Notwithstanding the mixed reviews on receptivity, the families were not discouraged and, in fact, predicted that their relationships with the schools will improve over time.

\section{Parent and Student Voices on Financial and Reimbursement Policies}

The development of financial policies and procedures has been constantly evolving and improving throughout the first-year implementation of the Program. Some initial confusion surrounding the finance issues clearly impacted the families. These issues, at times, dominated the focus group discussions. WSF has tried to clarify their policies to make it easier for both families and schools to understand how the financial and reimbursement procedures work. Some parents had benefited from these improvements and readily offered advice to other parents about the financial policies during the spring focus groups. 


\section{J. Parent and Student Voices on Satisfaction}

Similar to other choice programs, parents and students of the OSP expressed generally high levels of satisfaction with both their schools and the Program during the inaugural year. For satisfied participants, no single thread could be found connecting each family, although a few common themes included safety, smaller class sizes, and exposure to religious-based education. By the spring, a few parents and students became more willing to share sources of dissatisfaction with the participating schools, which may have been an effect of becoming more comfortable and knowledgeable with the Program or the focus group facilitators, or that the excitement of receiving a scholarship and beginning at a new school had slightly worn off. Sources of dissatisfaction centered mostly on particular disagreements with staff or teachers, although some parents also expressed concern that their child was not learning as much as they should, or was not adjusting fully to their new surroundings.

Even for those parents dissatisfied with their school selection, satisfaction with the Program overall remained quite high. While parents offered suggestions for improving program administration, none definitively indicated that they would remove their child from the OSP. Parents and students most often cited the opportunities that the Program created as the main reason for their satisfaction.

\section{Next Steps}

This report begins a discussion about school choice that attempts to tell a story about how 45 families experienced the first federally funded school voucher program. We have learned some valuable lessons that will guide the planning and organizing for year two of the Parent and Student Voices (PSV) study. As the first year research process unfolded from gathering to organizing, analyzing and ultimately presenting the data, the research team was struck by the complex and sometimes conflicting nature of the school choice experience as expressed by the participating families.

Our research revealed the difficulty of pinpointing where distinct elements of consumer behavior or communitarian activities begin and where they end. For example, during the focus groups, the parents discussed their involvement with school choice from four subtle, but profoundly different, perspectives: (1) how they learned about the OSP; (2) what motivated them to pursue OSP; (3) what factors they considered as they weighed the pros and cons of this opportunity; and, ultimately, (4) what factors influenced their final decision to participate. These are all similar, yet different, variations of one aspect of school choice - how parents decide. However, the popular research on this subject does not acknowledge the complexity involved with new families' experiences with school choice.

Given that student and parent experiences with schools is an annual process that families will complete and repeat again until their children leave the OSP or graduate from school, the families' experiences must be understood and assessed over time. We plan to continue our chronicle of Parent and Student Voices on the DC Opportunity Scholarship Program over the full five years of its proposed trial implementation. 
It should be noted that our greatest source of confidence in a longitudinal study stems directly from the exceptional levels of participation by the families who volunteered for this study. Not only have they participated in an extensive set of activities for a study of this type, they have expressed sincere interest in making sure that the public at large understands their experiences. We look forward to further exploring some of the topics highlighted above, as well as other topics that emerge from the experiences of families with the OSP. 


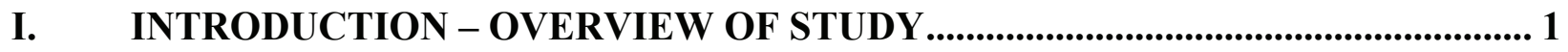

II. THEORY AND RESEARCH MEET PARENT AND STUDENT VOICES ............. 5

A1. Why are School Choice Programs Important?.................................................................................................6

A2. Parent and Student Voices on Their Introduction to Choice ..........................................................................7

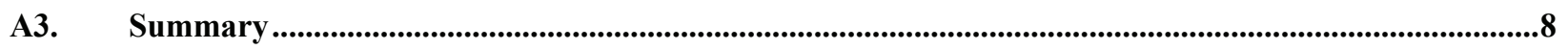

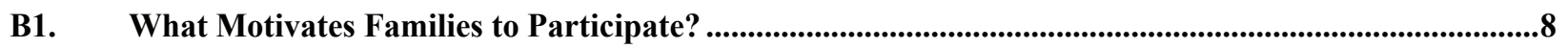

B2. Parent and Student Voices on What Motivates Families to Participate.....................................................9

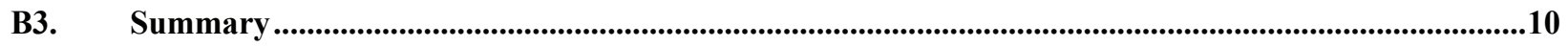

C1. What Do Families Look for in Private Schools? ..............................................................................................10

C2. Parent and Student Voices on What Families Look for in Schools...........................................................11

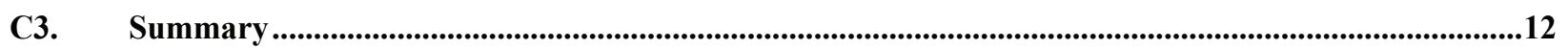

D1. How Important is Information? ........................................................................................................13

D2. Parent Perspectives on the Importance of Information ...............................................................................14

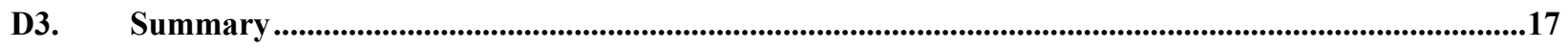

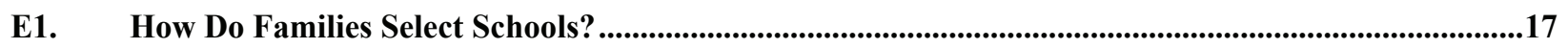

E2. Parent and Student Voices on School Selection ................................................................................................18

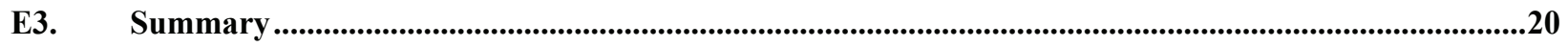

F1. What are the Components of the New Private School Environment? .......................................................21

F2. Parent and Student Voices on the New School Environment .....................................................................21

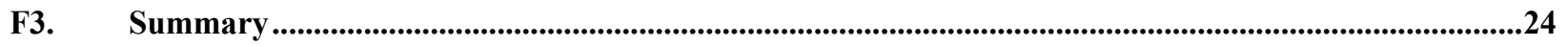

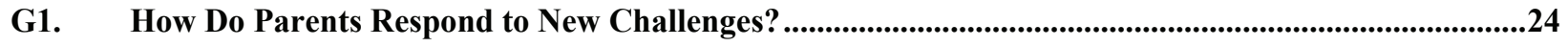

G2. Parent Voices on Responses to New Challenges ............................................................................................25

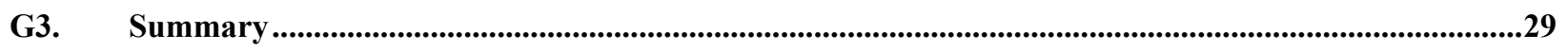

H1. Student-School Responses to New Challenges ...........................................................................................29

H2. Parent and Student Voices on Student-School Responses to New Challenges.........................................30

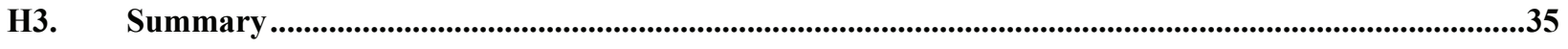

I1. How Does Finance and Reimbursement Policy Impact Choice Programs?.............................................36 
I2. Parent and Student Voices on Financial and Reimbursement Policy.........................................................36

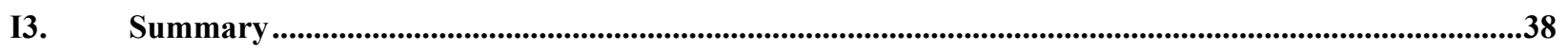

J1. Are Students and Parents Satisfied with School Choice? ................................................................................38

J2. Parent and Student Voices on Satisfaction and Most Memorable Experiences .......................................38

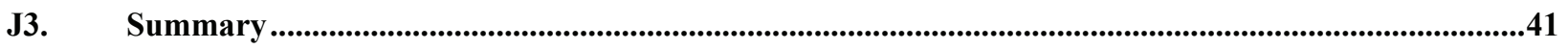

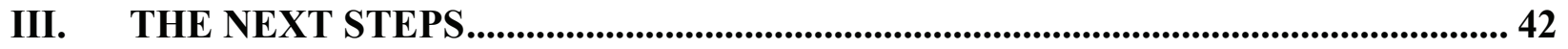

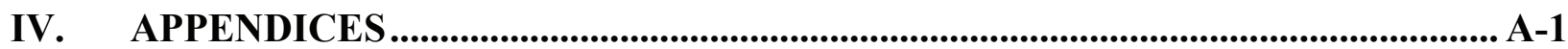

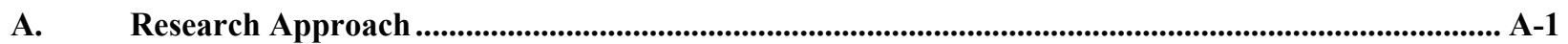

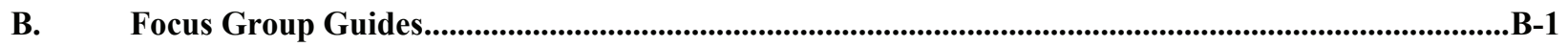

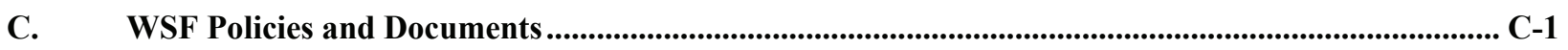




\section{INTRODUCTION - OVERVIEW OF STUDY}

On January 23, 2004, President Bush signed the DC School Choice Incentive Act into law. ${ }^{6}$ This landmark piece of legislation included $\$ 14$ million in funding for what would come to be called the DC Opportunity Scholarship Program (OSP). The OSP is the first federally funded K-12 scholarship program in the country.

The OSP was designed to provide approximately 1,700 DC children, whose families have annual household incomes below 185 percent of the poverty level (about $\$ 36,000$ for a family of four), tuition scholarships worth up to $\$ 7,500$ to attend participating $\mathrm{K}-12$ nonpublic schools in the District of Columbia. These scholarships may be used to pay tuition, fees, and transportation expenses, enabling families to enroll in participating District private elementary or secondary schools of their choice. ${ }^{7}$ Scholarships are renewable for up to 5 years, as long as families remain eligible for the Program and remain in good academic standing at the schools they are attending.

The law also charged the U.S. Secretary of Education and the Mayor of the District of Columbia with selecting both a program implementer and an independent evaluator of the Program. Using competitive bidding processes, in March of 2004 the Department selected the Washington Scholarship Fund (WSF) and its organizational partners as the program implementer and a research consortium including Westat, Georgetown University, and Chesapeake Research Associates as the official program evaluators. WSF began partial implementation of the OSP in the spring and summer of 2004, and the official evaluators issued their initial report on program implementation and participation in April of $2005 .^{8}$

The official baseline report highlighted the fact that program implementation began late in the spring, compared to previous scholarship initiatives. ${ }^{9}$ Thus, the families that received scholarships in most cases had roughly three months to conduct their school search and obtain placements in their schools of choice. This factor should be kept in mind when considering the responses of parents to questions about their school search and the placement process. In spite of a short time-line for first-year program implementation, over 1000 students, representing 75 percent of the total number awarded scholarships, used them to attend private schools of choice in the fall of $2005 .^{10}$

\section{The Impetus Behind the Parent and Student Voices Research}

The official government-sponsored evaluation of the OSP will focus almost exclusively on quantitative and experimental analyses of the effects of the Program on student test-scores, educational attainment, school safety, parental satisfaction, and survey research regarding the

\footnotetext{
${ }^{6}$ Title III of the District of Columbia Appropriations Act of 2004, Division C of HR 2673, 118 Stat. 117, D.C Code Sec. 38-1851.01.

${ }^{7}$ DC School Choice Incentive Act of 2003, Sec. 313.

${ }^{8}$ Patrick Wolf, Babette Gutmann, Nada Eissa, Michael Puma, and Marsha Silverberg, Evaluation of the DC Opportunity Scholarship Program: First Year Report on Participation U.S. Department of Education, National Center for Education Evaluation and Regional Assistance (Washington, DC: U.S. Government Printing Office, 2005), pp. 1-18.

${ }^{9}$ Ibid., p. 11.

${ }^{10}$ Ibid., p. 30.
} 
public school response to competition resulting from the transfer of students from DC public schools to private schools. Such rigorous quantitative program evaluations are essential for informing the policy debate surrounding school choice. At the same time, quantitative evaluations necessarily abstract from the contextual nuance of what is happening in the lives of the families experiencing the Program.

To chronicle the real-life experiences of OSP families, we sought and received foundation support for a qualitative study of the Program. The Parent and Student Voices (PSV) study is informed by focus group sessions and semi-structured personal interviews. ${ }^{11}$ The purpose of these qualitative methods is to further explore the participants' attitudes, feelings, beliefs, and experiences in a way that cannot be fully captured by the quantitative methods being employed in the official evaluation. ${ }^{12}$

The focus groups were used as the primary data gathering technique for this particular study of the Program. During the exploratory phase, which is covered by this first report, the focus groups were used to build trust and rapport, develop and refine questions, and illuminate key themes regarding family experiences with the OSP. In later stages of the study, the focus groups will allow respondents on-going opportunities to collectively reflect upon and explore salient experiences, including how their experiences persist or change over time. ${ }^{13}$

We acknowledge the limitations of such qualitative research. Participating families are self-selected in a number of ways, including their desire to apply for an Opportunity Scholarship and their willingness to discuss their experiences in a group setting. The statements and experiences of the families in this study are not necessarily representative of all OSP families or the broader population of low-income urban parents and students.

The research discussed below is entirely separate from the official government evaluation supervised by the U.S. Department of Education's Institute for Education Sciences. This discrete evaluation neither contributed resources to that official evaluation nor drew directly from any information gained from the official study. The Parent and Study Voices study is an independent research project undertaken by the School Choice Demonstration Project (SCDP) at Georgetown University's Public Policy Institute. It is funded entirely by a grant from the Annie E. Casey Foundation. $^{14}$

\footnotetext{
${ }^{11}$ Focus groups have been used as an effective tool for measuring the impact of public policy. See for example: Caroline Dyer, "Researching the Implementation of Educational Policy: A Backward Mapping Approach," Comparative Education, 35:1 (1999), pp. 45-61.

${ }^{12}$ D.L. Morgan, Focus Group as Qualitative Research. $2^{\text {nd }}$ Ed. (London: Sage, 1997); D.W. and P.N. Shamdasani, Focus Groups: Theory and Practice (London: Sage, 1992).

${ }^{13}$ Focus groups can be a very powerful way to uncover the view of unique populations like children. See for example: M.J. Hoppe, E.A. Wells, D.M. Morrison, M.R. Gilmore, and A. Wilsdon, "Using Focus Groups to Discuss Sensitive Topics with Children," Evaluation Review, 19:1 (1995), pp. 102-114.

${ }^{14}$ We thank the Annie E. Casey Foundation for their support, but acknowledge that the findings and conclusions presented in this report are those of the authors alone, and do not necessarily reflect the opinions of the Foundation.
} 


\section{Research Methodology}

During the WSF general orientation for first year families, in the early fall of 2004, parents attending the meetings were informed about how this aspect of the evaluation differs from the testing and surveying of the official evaluation, highlighting the fact that their involvement would require an additional time commitment. They were informed that their participation in the Parent and Student Voices study would be completely voluntary; and that their identities and comments would be kept strictly confidential. Families were randomly selected from the pool of candidates who specifically volunteered.

The PSV study is based on conversations with forty-five (45) families, out of 230 families that volunteered from the general pool of roughly 350 families that attended the orientation. An equal number of families with elementary, junior high, and high school age students, as well as a group compromised of Spanish speaking families, were randomly selected and invited to participate in the focus groups. In addition to one parent from each family, middle and high school age students also were invited to participate in the focus group discussions.

The families had a wide range of characteristics, which included students who attended traditional public, public charter and a small number of private schools prior to enrolling in the Program. ${ }^{15}$ In addition, the families represented 7 of the District of Columbia's 8 Wards or geographical areas.

The SCDP research team conducted a total of 12 focus groups during the initial year of the study, six in the fall of 2004 and another six in the spring of 2005 . Each focus group session included an average of 10 participants and featured extensive tape-recorded dialogue among students, parents, and facilitators that each lasted about 90 minutes. The fall focus groups concentrated on the family experiences finding out about and pursuing the OSP, completing the application and eligibility processes, and thinking about and selecting new schools. In addition, there was some preliminary discussion about adjusting to the new schools in general.

The second round of focus groups centered on a deeper reflection upon the first year experiences. The respondents were encouraged to discuss the perceived effects that the school choice program had on children and their parents. Additional details regarding the study's research methodology and the demographic characteristics of participants are provided in Appendix A.

The purpose of this report is to share the story of the first year of OSP implementation from the perspective of the families that experienced it. To the extent possible, the information is presented in the participant's own words, though contributors are never identified by name, to protect their privacy. The focus groups were essentially informal conversations among lowincome inner-city families, some of whom are recent immigrants still learning the English language. To preserve the authenticity of the statements, we have done our best to present them verbatim.

\footnotetext{
${ }^{15}$ All of the families participating in the PSV study that had children who previously attended private schools did so using a partial-tuition scholarship before enrolling in the OSP.
} 
The conversations with the participating families and the subsequent findings reflect our enduring interest in understanding what actually happens when formerly excluded or nontraditional urban families participate in a new school choice program. The interest in this topic is best reflected by the burgeoning literature on school choice, which we discuss, in italics, at the start of each substantive subsection on study findings. 


\section{THEORY AND RESEARCH MEET PARENT AND STUDENT VOICES}

In the 50 years since economist Milton Friedman published "The Role of Government in Education" 16 scholars and policy makers have been debating how parental choice through market mechanisms can and does operate in education. Market "optimists" argue that education is a service that can be produced under a variety of arrangements and that parents are natural education consumers. ${ }^{17}$ Market "pessimists" argue that education is a public good that should be produced in government-run schools, and that school choice programs suffer "market failure" because only advantaged families will have the resources and experience to choose effectively. ${ }^{18}$

Fortunately, researchers have begun to study how market mechanisms like school choice work in practice, shedding light on a number of academic disputes and policy questions. Still, much remains to be learned about how low-income families respond to the new opportunities made available to them through school choice programs. Bruce Fuller and his colleagues claim that "Many policy wonks and commentators know very little about the cultural logics employed by different types of families as parents attempt to make sense of, and benefit from," public school choice arrangements. ${ }^{19}$ Moreover, how school choice programs are designed, and the real-world context in which they are implemented, appears to strongly influence their success. ${ }^{20}$

Our purpose in holding focus group discussions with parents and students who are participating in the OSP is precisely to better understand the reality within which this new school choice program is operating. As Laura Hamilton and Kacey Guin argue, "it is important to understand how parents balance the various outcomes as well as processes when they select schools." 21 Like Amy Stuart Wells, who conducted interviews with inner-city participants in a voluntary school busing program in St. Louis, we sought to "get past simplistic generalizations and make sense of the complex school choice processes from the perspective of the people

\footnotetext{
${ }^{16}$ Milton Friedman, "The Role of Government in Education" in Robert Solo (ed.), Economics and the Public Interest (Rutgers, NJ: Rutgers University Press, 1955).

${ }^{17}$ See Milton Friedman, Capitalism and Freedom (Chicago: University of Chicago Press, 1962); John E. Chubb and Terry M. Moe, Politics, Markets, and America's Schools (Washington: Brookings, 1990).

${ }^{18}$ See John Dewey, Democracy and Education (New York: Macmillan, 1916); Amy Gutmann, Democratic Education (Princeton, NJ: Princeton University Press, 1987); Helen F. Ladd, Market-Based Reforms in Urban Education (Washington, DC: Economic Policy Institute, 2002); Henry L. Levin, "Educational Vouchers:

Effectiveness, Choice, and Costs," Journal of Policy Analysis and Management. 17, (June 1998).

${ }^{19}$ Bruce Fuller, Richard F. Elmore, and Gary Orfield, "Policy Making in the Dark: Illuminating the School Choice Debate," in Bruce Fuller and Richard F. Elmore (eds.), Who Chooses? Who Loses? Culture, Institutions, and the Unequal Effects of School Choice (New York: Teachers College Press, 1996), p. 13.

${ }^{20}$ Henig, Rethinking School Choice..., pp. 22, 232; Fuller et al., "Policy Making in the Dark..." pp. 12-13; Richard F. Elmore and Bruce Fuller, "Empirical Research on Educational Choice: What are the Implications for PolicyMakers?" in Bruce Fuller and Richard F. Elmore (eds.), Who Chooses? Who Loses? Culture, Institutions, and the Unequal Effects of School Choice. (New York: Teachers College Press, 1996), p. 200; James Harvey and Lydia Rainey, Doing Choice Right: Proceedings of a Meeting on Communities and Choice (Center on Reinventing Public Education: University of Washington, 2004) p. 10.

${ }^{21}$ Laura Hamilton and Kacey Guin, "The Demand Side of School Choice: Understanding How Families Choose Schools," in Julian Betts and Tom Loveless, Getting Choice Right: Ensuring Equity and Efficiency in Education Policy (Washington: Brookings, 2005) p. 16.
} 
making the decisions." 22 After all, if one wants to know why and how parents and students choose schools, why not ask the participants themselves?

The OSP, therefore, offers a rare contemporary opportunity to examine prominent theories and advance research on school choice. Each section of this report begins with a summary of previous school choice research findings on that particular topic in an attempt to place the parent and student voices into a broader and deeper context. After each summary, we present the salient findings from the first year qualitative evidence. As noted above, there were 12 focus groups with parents (8) and students (4). We first analyzed the transcripts from each focus group, specifically teasing out the salient and varied responses within each group. Once the individual focus group summaries were completed, the entire research team met to compare and contrast the findings across the four groups.

It should be noted that in an attempt to clarify or verify the information provided by the students and parents, a group of staff members from WSF were interviewed, and eleven personal telephone interviews were conducted with school representatives from participating schools. When and where necessary, their views and insights on the issues are included to provide a more comprehensive and updated perspective on the issue.

\section{A1. Why are School Choice Programs Important?}

The OSP is a parental school choice program targeted to low-income families living in the District of Columbia. It permits parents to send their children to private schools, of their choosing, at public expense. As Jeffrey Henig has observed, "The word 'choice' is a potent political symbol. Its connotations of personal freedom and abundance of opportunities make it a slogan that is easy to rally around. "23 As Americans, we tend to view individual choice as a good thing, unless it results in unsuspecting consumers getting "ripped off" or some general societal harm - what economists refer to as a "negative externality."

School choice is not limited to places with K-12 scholarship programs, such as Milwaukee, DC, and the states of Ohio, Florida, and Utah. As Elmore and Fuller point out, "Choice is everywhere in American education. It is manifest in the residential choices made by families with school-age children; it is capitalized in the housing prices found in neighborhoods. "24 Since most school children are assigned to a public school based on where they live, housing markets play a very important role in American education, so much so that Patrick Wolf has argued: "School choice and residential assignment are both marketbased methods for allocating students to schools. "25

\footnotetext{
${ }^{22}$ Amy Stuart Wells, “African-American Students' View of School Choice," in Bruce Fuller and Richard F. Elmore (eds.), Who Chooses? Who Loses? Culture, Institutions, and the Unequal Effects of School Choice (New York: Teachers College Press, 1996), p. 31.

${ }^{23}$ Jeffrey R. Henig, Rethinking School Choice: Limits of the Market Metaphor (Princeton, NJ: Princeton University Press, 1994), p. 21.

${ }^{24}$ Richard F. Elmore and Bruce Fuller, "Empirical Research on Educational Choice: What are the Implications for Policy-Makers?" in Bruce Fuller and Richard F. Elmore (eds.), Who Chooses? Who Loses? Culture, Institutions, and the Unequal Effects of School Choice (New York: Teachers College Press, 1996), p. 187.

${ }^{25}$ Patrick J. Wolf, "Comment on 'School Choice: How an Abstract Idea Became a Political Reality," in Diane Ravitch (ed.), The 2004 Brookings Papers on Education Policy (Washington: Brookings, 2005), p. 164.
} 
As an alternative to school assignment by residence, school choice programs hold the prospect of correcting some of the "market failures" associated with a reliance on real estate markets to match students with schools. After all, low-income families may not view their neighborhood public school as a desirable place for their children to be educated, and they tend to lack access to private schooling or high-priced residential areas with more attractive schools. However, the extent to which school choice programs operate democratically and effectively to place students in appropriate schools depends heavily on the willingness and ability of participating families to operate as responsible education consumers.

\section{A2. Parent and Student Voices on Their Introduction to Choice}

Almost all of the parents expressed considerable excitement about the ability to pursue educational options for their children. Most parents equated school choice with opportunity. They consistently cited the significance of having greater control over their child's education and expressed gratitude for the financial support that allowed them choice amongst a variety of schools beyond the limited options they had previously experienced prior to the OSP. Following are some of the comments shared during the winter and spring focus groups:

Parent: What's most important is the education, the opportunity to have another type of education, an option. ${ }^{26}$

Parent: They [scholarships] give you the opportunity to choose from several schools. You know you're not just stuck with one school. They offer several schools to choose from, I think that's very good. ${ }^{27}$

Parent: This is what I tell my kids: I tell them that this is an opportunity for you to strive, do your best, take advantage of it, that's what I tell my children. ${ }^{28}$

Parent: This is a blessing. ${ }^{29}$

From the students' perspective, the OSP helped them avoid undesirable educational situations and improved their chances for success. The middle school students were especially vocal about the opportunity to explore private school options, as one respondent noted:

Student: It helps us get into a better school to help us learn more. ${ }^{30}$

Only a few parents reported that they had explored other options prior to the OSP. Those who had explored other avenues of choice did so through charters and private schools. Most of those who had children previously in private schools mainly relied on the long-standing partialtuition private scholarship program offered by the Washington Scholarship Fund.

\footnotetext{
${ }^{26}$ PSV Focus Group, Parents of Hispanic Students, Winter 2004.

${ }^{27}$ PSV Focus Group, Parents of High School Students, Winter 2004.

${ }^{28}$ PSV Focus Group, Parents of Elementary School Students, Spring 2005.

${ }^{29}$ PSV Focus Group, Parents of Elementary School Students, Spring 2005.

${ }^{30}$ PSV Focus Group, Middle School Students, Spring 2005.
} 
The majority of parents reported that they were not actively involved in the process to create the DC Opportunity Scholarship Program and were not aware that such a program was in the making. Instead, parents found out about the Program during the marketing and outreach efforts, which included direct mailings and fliers; word-of-mouth through friends, family, schools, and churches; and advertisements on buses, television, radio, and in the newspapers. In some cases, parents just happened upon the information. In a small number of instances, active searching led parents to the Program:

Parent: $\quad$ Since I was constantly looking for financial assistance, I went to libraries and I asked a lot of people. It was suggested that I applied to this program. Then I read the ads in the newspaper, which finally convinced me to take a shot and apply. ${ }^{31}$

\section{A3. Summary}

The role of parents as consumers of educational options is an essential feature of the school choice debate. Prior to the creation of the OSP, the vast majority of families in this study had not explored educational opportunities beyond the traditional public school their children were formally assigned. This suggests that most of them had limited experience exercising the consumer behavior implicit in school choice. However, once these families learned about the OSP, particularly the schools that were involved, they became immediately excited about the opportunity. It appears that the freedom to actively choose among the range of school options was the most important reasons why families' pursued the OSP.

\section{B1. What Motivates Families to Participate?}

There is general agreement that parents seek educational choices beyond their assigned neighborhood public school because they are looking for a better educational alternative for their children. Fuller and his colleagues conclude that, "When benefits are targeted to lowincome families, many parents do actively choose a school that they believe better fits their educational agenda than does the neighborhood school." 32 As Henig writes, "Even under the best of circumstances, the neighborhood public school will not adequately serve the needs of every neighborhood child. This can be due to the particular characteristics of the child, the particular limitations of the school, or a simple lack of fit between one and the other." 33

There is some disagreement, however, regarding whether choice families tend to be primarily running away from a bad schooling situation or running toward a good one. Lowincome parents and students in urban neighborhood public schools frequently report disturbing levels of violence in their schools, and resulting concerns about student safety. ${ }^{34}$ At the same time, a survey of the literature on why parents choose schools suggests that a better educational program, a religious educational environment, and a better match between the cultural values of

\footnotetext{
${ }^{31}$ PSV Focus Group, Parents of Hispanic Students, Winter 2004.

${ }^{32}$ Fuller et al, "Policy Making in the Dark..., p. 9.

${ }^{33}$ Henig, Rethinking School Choice..., p.206.

${ }^{34}$ Wells, “African-American Students' View of School Choice...," pp. 43, 45; Wolf et al, Evaluation of the DC Opportunity Scholarship Program..., p. C-5. William G. Howell and Paul E. Peterson, with Patrick J. Wolf and David E. Campbell, The Education Gap: Vouchers and Urban Schools (Washington: Brookings, 2002), pp. 110112.
} 
the family and school are often motivators for choosing. ${ }^{35}$ Obviously, school choosers are looking for a change. Whether they are mainly seeking to escape from a bad situation or are simply interested in a distinct school that might be a better fit for their child remains an open question.

\section{B2. Parent and Student Voices on What Motivates Families to Participate}

Parents stated that they were motivated to apply to the OSP for a variety of reasons; the most common being that they thought choice would allow them to obtain a better education for their child. Some parents, for example, sought choice because they wanted their children to be challenged academically:

Parent: And he's very intelligent as well and he needed to be challenged. ${ }^{36}$

Many parents were also motivated by a perception of improved safety. Several stated that they believed private schools would have less violence and stricter discipline than the public schools. In some cases, closely tied to this notion was a desire to place their child in a religious or values-based educational environment:

Parent: $\quad$ Religion was very important for us because that helps for the culture of the child. $^{37}$

Parent: I like my children to go to a school where religious education is taking place because I believe religion will discipline the children. ${ }^{38}$

Students, on the other hand, tended to focus on the Program as a better opportunity when describing their views on what motivated their family to participate. Nonetheless, slight frustration or dissatisfaction with their previous educational environment seemed to underlie many of their comments:

Student: $\quad$ The scholarship helps you go to like a better school where you don't have to worry about all of that nonsense. ${ }^{39}$

Student: It gave you a way out of nowhere. You're not used to being on top of everything, or you're not the person- you're not the one that got the killer jump shot- but you're still trying to go somewhere and go to school and get away from this environment and you've got that opportunity to use your scholarship. ${ }^{40}$

\footnotetext{
${ }^{35}$ Valerie Martinez, Kenneth Godwin, and Frank R. Kemerer, "Public School Choice in San Antonio: Who Chooses and with What Effects?" In Bruce Fuller and Richard F. Elmore (eds.), Who Chooses? Who Loses? Culture, Institutions, and the Unequal Effects of School Choice (New York: Teachers College Press, 1996), p. 54.

${ }^{36}$ PSV Focus Group, Parents of Elementary School Students, Winter 2004.

${ }^{37}$ PSV Focus Group, Parents of Hispanic Students, Spring 2005.

${ }^{38}$ PSV Focus Group, Parents of High School Students, Fall 2004.

${ }^{39}$ PSV Focus Group, Middle School Students, Spring 2005.

${ }^{40}$ PSV Focus Group, High School Students, Spring 2005.
} 
In addition to the motivation behind their own participation, parents also speculated why other families may not have participated in the program. Several parents commented that the legal requirements, such as residency restrictions, as well as the long list of required documents was overly burdensome and likely prevented some families from applying. Most felt that with increased outreach and clearer information (a topic discussed in later sections), this barrier to motivation and participation could be overcome.

\section{B3. Summary}

The popular literature strongly suggests that parents who seek choice are primarily motivated by a desire to provide their children with the best education possible. Generally speaking, the families in this study were driven by such a desire. However, when challenged to provide more detailed information about the sources of their motivation, their responses suggested that the OSP was an extremely rare opportunity and they were prepared to overcome any real or perceived obstacles to seize it. Rather than citing the limitations of their prior educational experiences as a source of motivation, most cited reasons that suggested they were seeking a better opportunity. These reasons will be discussed in greater detail below.

\section{C1. What Do Families Look for in Private Schools?}

The specific school preferences that choosing parents have is central to the debate about the efficacy and desirability of school choice programs. As Fuller and his colleagues argue, "choice schemes assume that the family is highly rational, acts from clear preferences, and is able to effectively demand action from local schools and teachers. "4l If parents do not really know what to look for in a school, or they seek objectionable conditions such as racial uniformity, then their educational choices will be unlikely to result in educational benefits for their child or society in general.

One issue about which researchers disagree is the extent to which all choosing parents prefer the same thing or preferences vary across individuals or groups of parents. Edward Fisk and Helen Ladd claim that parents appear to be uni-dimensional in their preferences for schools. They rank schools consistently in their "quality," and define quality exclusively based on the socio-economic status of the student body. ${ }^{42}$ Elmore and Fuller agree that choosing parents "seem to have preferences that are remarkably similar across race and social class.",43 Mark Schneider and Jack Buckley discovered that, when searching DC public schools on the Internet, parents frequently searched on the demographics of the student body and honed in on schools with lower percentages of African-Americans as their searches deepened. ${ }^{44}$ Gill and his colleagues, in a review of the school choice literature, conclude that, where choice programs are available to a significant number of white students, white parents tend to select schools "with fewer minority students, whereas minority families tended to request transfers to schools with

\footnotetext{
${ }^{41}$ Fuller et al, "Policy Making in the Dark...," p. 3.

${ }^{42}$ Edward B. Fiske and Helen F. Ladd, When Schools Compete: A Cautionary Tale (Washington: Brookings, 2000), pp. 195-198.

${ }^{43}$ Elmore and Fuller, "Empirical Research on Educational Choice...," p. 192.

${ }^{44}$ Mark Schneider and Jack Buckley, "What do Parents Want from Schools? Evidence from the Internet," Educational Evaluation and Policy Analysis, 24:2, (2002).
} 
higher proportions of minority students." 45 Elmore and Fuller conclude that there is "little evidence that active choosers are looking for distinctive educational programs when they make their choices." 46

These studies of parental preferences all took place within the context of choice programs that were open to all families, regardless of income and race. It may be that lowincome African American families, in particular, seek conditions besides the socio-economic status and race of peers when selecting schools. Several studies of means-tested school choice programs suggest that may be the case. In reviewing an important study by Saporito and Lareau, Hamilton and Guin conclude that "race was not a factor in [African American's] school choice decisions. School poverty rates, however, did have a modest impact on the schools selected by African-Americans families." 47 They continue "Many parents believe that peer effects (the average ability of the child's schoolmates) and resources (e.g. class size) are important determinants of student outcomes, and therefore are likely to emphasize these factors if they have information on them." 48 Schneider and his colleagues go even farther in concluding that "Lower socioeconomic status and minority parents are more likely to value schools that perform the bedrock function of providing a safe environment and the fundamentals of education. "49 Their claims are consistent with two experimental evaluations of means-tested school choice programs in Washington, DC, that have found that parents who choose schools are most likely to describe "academic quality" as the most important reason for their selection, with school safety, discipline, and location as additional important concerns. ${ }^{50}$

We still need to learn more about the schooling preferences of low-income parents participating in school choice programs. The evidence to date suggests that they have a strong preference for academic quality in the schools they select, with a diverse set of secondary preferences centered on order and discipline as well as convenience.

\section{C2. Parent and Student Voices on What Families Look for in Schools}

Parents cited a variety of reasons for selecting schools under the auspices of the OSP. The most common considerations that parents pointed to were school safety and a religious or values-based educational environment. In addition, parents were seeking a more rigorous academic curriculum, smaller classes, the opportunity to learn foreign languages, and private schools in close proximity to their home. One parent commented on what she saw as a positive change in the curriculum and educational environment of private schools:

\footnotetext{
${ }^{45}$ Brian P. Gill, P. Michael Timpane, Karen E. Ross, and Dominic J. Brewer, Rhetoric Versus Reality: What We Know and What We Need to Know About Vouchers and Charter Schools (Santa Monica, CA: RAND, 2001), pp. 173-174.

${ }^{46}$ Elmore and Fuller, "Empirical Research on Educational Choice...," p. 199.

${ }^{47}$ Hamilton and Guin, "The Demand Side of School Choice...," p. 7.

48 Ibid., p. 16.

${ }^{49}$ Mark Schneider, Paul Teske, and Melissa Marschall, Choosing Schools: Consumer Choice and the Quality of American Schools (Princeton, NJ: Princeton University Press, 2000), p. 107.

${ }^{50}$ Patrick Wolf, Babette Gutmann, Nada Eissa, Michael Puma, and Marsha Silverberg, Evaluation of the DC Opportunity Scholarship Program..., p. C-7; Patrick J. Wolf, Paul E. Peterson, and Martin R. West, Results of a School Voucher Experiment: The Case of Washington, D.C., After Two Years, Harvard University Program on Education Policy and Governance, PEPG/01-05 (Cambridge, MA, August 2001), Table 3.
} 
Parent: The curriculum is very different and the language is very different. When I looked at the difference and I said to them that this school [what they're doing] is preparing them to go to college and be executives versus, and it's nothing wrong with it but, being blue collar workers. ${ }^{51}$

A significant number of parents believed that smaller class sizes in private schools allow their children to receive greater attention from teachers as suggested by this respondent:

Parent: I'm interested in better education for my son and I know that will be done not necessarily in public schools, but in private school in a smaller, more formal atmosphere. ${ }^{52}$

A small number of parents noted that they wanted their children to have experiences outside of their immediate neighborhood, which would include schools that have racially diverse student populations or strong foreign language programs:

Parent: Actually, I wanted my child to be in a school setting where it was racial diversity. I didn't want it to be where she would just see her color. ${ }^{53}$

Parent: I wanted my daughter to start very early to learn the Arabic language and in this private school where she is, they have that. She's taught in both English and Arabic. $^{54}$

Parent: I wanted them to learn another language, other than English, so my daughter is learning Spanish in the kindergarten. I didn't learn it until I was grown. ${ }^{55}$

\section{C3. Summary}

The quantity and quality of school options available to families is another essential element of the school choice debate. Theoretically, all parents seek schools that will help their children achieve high academic standards. Somewhat contrary to some of the popular literature, families in the early stages of their experiences with the OSP were less concerned about academic outcomes - none of them mentioned having researched a school's student test scores -and more focused on academic environment and the basic conditions for learning. School safety, student discipline, and the religious nature of the school all were among the most important considerations for these first-year families. School safety and student discipline were particularly important for parents with older children. This is a topic we anticipate parents will want to revisit as their children move from different grades within the same school, or as they move from middle to high school. Thus, we will explore it further in future parent focus groups.

\footnotetext{
${ }^{51}$ PSV Focus Group, Parents of Middle School Students, Spring 2005.

${ }_{52}^{52}$ PSV Focus Group, Parents of Elementary School Students, Winter 2004.

${ }^{53}$ PSV Focus Group, Parents of Elementary School Students, Fall 2004.

${ }^{54}$ PSV Focus Group, Parents of High School Students, Fall 2004.

${ }^{55}$ PSV Focus Group, Parents of Elementary School Students, Fall 2004.
} 


\section{D1. How Important is Information?}

Information is central to consumer activity in any context. Shoppers rely on the information on clothing labels to assess the fit and quality of an outfit, and the information on packaging to determine the likely taste and nutritional value of the food that they buy. Magazines such as Consumer Reports and countless Internet sites provide guidance and comprehensive consumer information to eager subscribers and web-surfers. There is general agreement that informed consumers help to make markets work properly. According to Hamilton and Guin, "A critical factor influencing parental choice behaviors is the quality of information available to parents on the schools that operate within the choice system." Highquality and accessible information supports educational markets by avoiding or minimizing "information asymmetry" between suppliers and consumers. ${ }^{57}$ Well-informed consumers are more likely to match their children to appropriate schools. If parents are primarily interested in academic quality, the presence of a large group of well-informed choosers will pressure schools to improve the quality of their educational product. The main areas of disagreement surround the questions of what school information sources are most helpful, how much information is enough, and how many choosers need to be well informed in order for schools to respond in desirable ways to their preferences?

The three most commonly discussed sources of consumer information about schools are information centers and guides, social networks, and personal site visits. Henig argues that general sources, such as information centers and school directories, are especially valuable because they are available to all parents, regardless of their personal resources. ${ }^{58}$ Citing several previous studies, Hamilton and Guin suggest that "social networks, including extended family and friends, are a primary source of information about schools for many parents. "59

Just as car-buyers are frequently advised to take a new car for a test drive before purchasing, parents are typically advised to visit schools before selecting one for their children. In her study of a voluntary busing program, Wells found that none of the families she interviewed had a chance to visit the suburban choice schools before making their selections. As a result, "Transfer parents and students lacked information about the 16 county districts and about particular schools, suggesting they were not making the best choice but rather making the best choice possible given the limited amount of information available. "60

Although research has been unable to pinpoint exactly how much information is necessary to be an effective educational consumer, there is general agreement that more is better. Families that are able to gather information from multiple sources and visit several

\footnotetext{
${ }^{56}$ Hamilton and Guin, "The Demand Side of School Choice...”, p. 9.

${ }^{57}$ Information asymmetry occurs when one party to a transaction, either the buyer or the seller, has significantly better information than the other regarding the quality of the product and the true cost of producing it. For background on the theory of information asymmetry, see for example William A. Niskanen, Jr., Bureaucracy and Representative Government (Chicago: Aldine-Atherton, 1971); Armen A. Alchian and Harold Demsetz, "Production, Information Costs, and Economic Organization," American Economic Review, 62 (1972); and Terry M. Moe, "The New Economics of Organization," American Journal of Political Science, 28 (1984).

${ }^{58}$ Henig, Rethinking School Choice..., p. 210.

${ }^{59}$ Hamilton and Guin, "The Demand Side of School Choice...," p. 10.

${ }^{60}$ Wells, “African-American Students' View of School Choice...," p. 36.
} 
different schools will likely be able to separate the more reliable from the less reliable information and draw accurate contrasts between various educational suppliers and products.

School choice researchers disagree, however, regarding how many educational consumers need to be well-informed in order for schooling providers to be motivated to provide a high-quality educational product to choosers. Early school choice proponents tended to claim that all choosers need to be well-informed. ${ }^{61}$ Schneider and his colleagues later introduced the concept of the "marginal consumer." The marginal educational consumer is the especially wellinformed parent that has access to lots of high quality information about schools and conducts multiple school visits. Based on their empirical research, Schneider and his colleagues argue that only a relatively small sub-set of school choosers need to be marginal consumers in order for most participating schools to be pressured to offer a quality educational program. ${ }^{62}$ According to these researchers, even less-informed choosers can find their way into good schools so long as marginal consumers do their school-choice homework.

\section{D2. Parent Perspectives on the Importance of Information}

Most of the parents asserted that accurate and comprehensive information was critical to their ability to make thoughtful and confident school choices. In the beginning stages of the OSP, quality information about the Program and the participating schools emerged as an extremely important point of discussion within the focus groups. Parents relied on a variety of information sources including WSF, public and private schools, other parents and friends, and prior knowledge.

Parents were generally impressed with the frequency and quality of communication they received from WSF, for example:

Parent: The level of communication, letters, phone calls, follow-up letters, follow-up phone calls...I mean sometimes we are busy and we need that. I liked the followup...just sometimes it might seem like a little much but I like it. ${ }^{63}$

Most parents found the information packets provided by WSF to be very useful in finding a school, especially the directory on participating schools. The WSF "School Directory" provided parents with general information on each participating school, including location, contact information, grade offering, services and facilities, admissibility criteria, religious affiliation (if any), local transportation, as well as basic information on teachers, students, and the application process. As one respondent noted:

\footnotetext{
${ }^{61}$ See, for example, Chubb and Moe, Politics, Markets, and Schools...; John E. Coons and Stephen D. Sugerman, Education by Choice: The Case for Family Control (Berkeley, CA: University of Berkeley Press, 1978).

${ }^{62}$ Schneider et al, Choosing Schools..., pp. 172-176.

${ }^{63}$ PSV Focus Group, Parents of High School Students, Winter 2004.
} 
Parent: That packet of information that gave us all the schools that were available and information about each school...where they were located, what facilities they had, if they had a gym or a library, they had music, language program, drama, my kids are artists so I wanted a school that had all that. ${ }^{64}$

Several parents suggested that future directories also specify whether or not the school offers hot lunch (or is able to heat lunches) and include more detailed information on fundraising requirements. A middle school parent postulated that this information might prevent the surprise that one parent felt after school selections had been made:

Parent: When we came for the orientation... a lady sat up and said we have a fundraiser and the parents have to participate and even if you don't participate you still have to pay the $\$ 200$...I was like excuse me. ${ }^{65}$

A few parents also requested additional information about the Program itself. These requests included clarification on the rules and regulations of the OSP, such as what would happen if their family income increased, as well as information and advance notice of upcoming school and Program events.

In addition to WSF, participating schools were also a major source of information for parents. The school fair and site visits allowed parents to get first-hand information on their child's potential educational environment. Due to time constraints, however, not all parents were able to take advantage of this source of information:

Parent: I didn't really have enough time like other parents to check out the curriculum and visit the schools. ${ }^{66}$

While this information proved useful to many parents, a number of parents cited a need to make schools more accountable for the information they provide. One parent, for example, felt that despite efforts to be an educated consumer, the information provided by their school did not match up with reality:

Parent: Well I took my time. I checked with seven or eight schools. Now I am displeased because what I saw when I visited is not what I'm getting. ${ }^{67}$

To address this issue, some parents went so far as to say that WSF should verify that each school actually offers the services and programs they advertise:

Parent: WSF, if they would check into these schools you know just make sure they up to speed because if they on the same level as the public schools why should you pay them this amount? ${ }^{68}$

\footnotetext{
${ }^{64}$ PSV Focus Group, Parents of High School Students, Winter 2004.

${ }^{65}$ PSV Focus Group, Parents of Middle School Students, Winter 2004.

${ }^{66}$ PSV Focus Group, Parents of Elementary School Students, Winter 2004.

${ }^{67}$ PSV Focus Group, Parents of Elementary School Students, Winter 2004.

${ }^{68}$ PSV Focus Group, Parents of Elementary School Students, Spring 2005.
} 
As a second method of ensuring accountability, several parents suggested that WSF survey parents regarding what they liked and/or did not like about their schools given their experiences. $^{69}$ Some felt this would be an invaluable source of information for Program participants:

Parent: Have parents who have...participated in the Washington Scholarship Program rate the schools for other parents. ${ }^{70}$

The importance of accurate information also became apparent during the focus groups as a means to dispel misinformation or unwarranted fears about the OSP. In the first set of focus groups, several parents noted that a rumor was circulating suggesting that they would have to pay the scholarship money back to the government. Among participants, this fear seemed to be alleviated by the time of the spring focus group sessions, as reflected by one parent:

Parent: I thought it was going to be downhill for me...you're going to give me this money to send my child to school, what exactly do you want, am I going to have to send pints of blood every month? But nothing they don't...it's a whole lot better than I imagined. $^{71}$

Not all parents, however, felt that reliable and accurate information was permeating all sectors of the community. Hispanic parents, in particular, noted that the legal aspects of the Program could be made clearer and that other avenues of outreach, such as Hispanic radio, should be explored. One parent also noted that it was important to emphasize that participation in the OSP would not take money away from neighborhood schools:

Parent: Many people object to the program because they believe that the school from their neighborhood will stop receiving money, money that goes to my daughter instead. And that is not true. ${ }^{72}$

School administrators unanimously agreed on the importance of providing accurate information to parents in a timely manner. A few administrators went on to note that the parents must also take responsibility for reading the information they are provided and addressing any questions they have. In addition to the information about each school that was provided in the packet, some administrators thought parents should be better oriented and informed about the different culture of private schools, including an increased level of parental involvement. Both WSF and a number of school administrators believed that a separate school orientation process for OSP parents would ease the transition. WSF and administrators reported that the school fair was widely successful and that it provided parents with a quick turnaround time to find a school.

WSF noted that problems relating to information often arise when families choose not to read the material they distribute and when families move without providing WSF with new contact information. WSF was limited in providing information over the Internet because many

\footnotetext{
${ }^{69}$ In response to parental requests that WSF conduct parent surveys and publish a book of school ratings, WSF noted that it is not allowed to disseminate parental opinions on schools because of concerns of possible bias.

${ }^{70}$ PSV Focus Group, Parents of Elementary School Students, Winter 2004.

${ }^{71}$ PSV Focus Group, Parents of Elementary School Students, Spring 2005.

${ }^{72}$ PSV Focus Group, Parents of Hispanic Students, Winter 2004.
} 
of the families in the OSP do not have Internet access. In order to better serve families that do not read the material or access the Internet, WSF began holding family meetings in the spring, through the establishment of a parent empowerment group. The empowerment group is open to all OSP parents and meets on a monthly basis to provide information and answer questions.

WSF did not independently verify the accuracy of information provided by schools participating in the OSP. WSF did employ a fiscal accountability system to ensure that participating schools complied with Generally Accepted Accounting Principles (GAAP) and applicable laws pertaining to the collection of tuition and fees (See Appendix C1).

\section{D3. Summary}

During the focus group discussions, accurate and timely information about the Program and the participating schools emerged as an important point of discussion. Similar to Henig's earlier findings, the most discussed sources of information for OSP parents included WSF guides, participating schools, friends, and other scholarship families. Most parents expressed satisfaction with the quality and quantity of information provided by WSF, although they generally agreed with the notion that "more is better." Those who attended the school fair and/or visited schools felt they were better equipped to make an informed choice. Several parents, however, shared fears that what parents see might not be what they get and suggested that an accountability process be instituted to minimize "surprises" once schools have been selected.

When asked, almost all parents agreed that other scholarship families are an untapped source of information about the OSP. This led to numerous suggestions that WSF have OSP parents write short descriptions about their schools that would be made available for new and transferring scholarship users. Finally, the importance of information became apparent as a means of dispelling rumors and unwarranted fears about the Program. While the dissemination of accurate information seems to have alleviated many concerns within scholarship families, the discussion within the focus groups indicated that further outreach might be necessary within various sectors of the community.

\section{E1. How Do Families Select Schools?}

What advice does previous research offer regarding the school selection process? In general, it recommends that a wide variety of choices and lots of useful information be made available to families, that parents be given primary influence over the admission decision, and that the students themselves play a role in the selection. Hamilton and Guin conclude that "Parental choice is obviously constrained by the options available to them, and in many cases the options are quite limited." W3 When parents have a variety of schooling choices, for example schools in the suburbs as well as the inner-city, they are more likely to find a school that is a good fit for their child's particular needs. When choices are limited and the schools themselves make the admission decision, the chances of a desirable placement can be significantly reduced. For example, Fiske and Ladd report that not all parents in New Zealand's universal choice program had viable choices, given a shortage of alternatives and out-of-pocket expenses

\footnotetext{
${ }^{73}$ Hamilton and Guin, "The Demand Side of School Choice..., p. 20.
} 
required to enroll in desired schools. Since oversubscribed schools were allowed to choose their students, "Parental choice, in short, gave way to school choice.",74

There also is some evidence that involving students in the school choice can increase the likelihood that the school placement will persist or "stick." Reviewing evidence from their study of a San Antonio school choice program, Kenneth Godwin and Frank Kemerer suggest that, "When families were deciding whether to remain in or drop out of a choice program, the child played a major role in the decision. If the child had been involved in the original decision, had the same ambitions as the parents, and had close friends in the choice school, then the family was likely to remain in the program." 75 Thus, student preferences and advice can be an additional source of information for the savvy "marginal consumer" of educational options.

\section{E2. Parent and Student Voices on School Selection}

Before selecting a school, a vast majority of the parents attended school fairs sponsored by WSF. The school fairs served as a showcase of participating schools and it provided the opportunity for OSP families to meet with representatives and obtain information from participating schools.

School visits were typically optional, but some school administrators required parents and students to visit the school as part of the application process. Almost half of the parents in our focus group participated in one or two school visits. About 25 percent visited three to five schools, and 25 percent visited six or more schools. Many of those who visited a small number of schools reported that they were interested in specific schools based on prior knowledge. Thus, they focused their energy and effort exclusively on those schools.

The parents who visited three or more schools found it very helpful to view the atmosphere and facilities at the school and to talk to the principals and other administrators and teachers. One parent explained why she thought this approach was important:

Parent: It was very helpful to visit the school and talk to the admissions people and to get information about what the school offers, the program, it did help me. ${ }^{76}$

Parents expressed frustration with the timing of the selection process. ${ }^{77}$ In the first year of the Program, schools did not receive OSP applicants until May of 2004, when the normal application process had already been completed. ${ }^{78}$ By the time some parents made site visits, school had already let out for the summer:

\footnotetext{
${ }^{74}$ Fiske and Ladd, When Schools Compete..., pp. 8-9.

${ }^{75}$ R. Kenneth Godwin and Frank R. Kemerer, School Choice Tradeoffs: Liberty, Equity, and Diversity (Austin, TX: University of Texas Press, 2002), p. 41.

${ }^{76}$ PSV Focus Group, Parents of High School Students, Winter 2004.

77 School administrators also noted their frustration with the timing of the school selection activities.

${ }^{78}$ The DC School Choice Incentive Act was not enacted until the end of January, 2004, and the Program Implementer was not selected until late March. As a result of this delayed start, the application and school search periods were compressed, by necessity, during the first year of program implementation.
} 
Parent: I went to an empty school and the staff was there, that was helpful, but I'd like to see the kids interact with the teachers and that would have made my decision a little bit more easier. ${ }^{79}$

WSF noted that, in the future, it will be able to provide information to the families earlier than it did in the first year. Additionally, they will try to address parent suggestions pertaining to school information.

\section{a. Involvement of students in the application and school selection processes}

Most students had little involvement in the decision to apply for a scholarship, and they had minimal say in which school to attend after receiving a scholarship. In general, the students said that their parents had the ultimate decision-making power and they expected that their parents would make the best decision for them.

Most students did not know enough about the participating schools to have a strong preference for one high school over another. One high school student commented that she wanted to attend "any high school that would help me go to college.,"80

Some parents noted they did not want to inform their child about the OSP until after the lottery, so that the child would not be disappointed if they did not win a scholarship. A few parents, however, included their children in the process by taking them on site visits and arranging for them to speak with school principals:

Parent: She was there at the school to [inter]act with the kids and see if she liked it... at the end of the day the principal called me and told me how she did and when she got home I asked her and she said she liked it, so I told her that I would be applying for her to go to that school the next following year. ${ }^{81}$

Parent: I let both of our daughters participate in which schools we'd pick. We scheduled appointments to sit down and talk to the principals. They asked the principals questions and she gave them the news and she asked them questions and they got to choose. The principal enjoyed talking to them because she was like I really enjoyed talking to them. They asked me some important questions and they decided which school they wanted to go to. ${ }^{82}$

Parent: What he thinks matters. He has to be happy with his school for him to make progress. If we tell him that he has to go to a school because we want him there, he won't do well, he won't make good grades. He has to choose his school. We have to place him where he feels okay. ${ }^{83}$

\footnotetext{
${ }^{79}$ PSV Focus Group, Parents of High School Students, Winter 2004.

${ }^{80}$ PSV Focus Group, High School Students, Winter 2004.

${ }^{81}$ PSV Focus Group, Parents of High School Students, Winter 2004.

${ }^{82}$ PSV Focus Group, Parents of High School Students, Winter 2004.

${ }^{83}$ PSV Focus Group, Parents of Hispanic Students, Spring 2005.
} 


\section{b. Limits of choice: a dearth of high school options}

The limited availability of slots at the high school level and the number of private schools participating in the Program concerned several parents:

Parent: Just because there was a limited number of high schools, we had the chance only to see just a few schools for the high school. ${ }^{84}$

Other parents mentioned limitations of the scholarship lottery and offered some constructive suggestions for improving it. The most often cited suggestion was that the lottery should be family based. The parents recommended that if one student was awarded a scholarship, the other siblings should also be awarded scholarships:

Parent: Obviously if you need help with one kid you're going to need it with all your kids. $^{85}$

Parent: I have foster kids so my whole family is a total of six and four got in. Two didn't, so I just appreciated the four. The two that didn't I didn't complain 'cause four did get it. ${ }^{86}$

Some of the other reasons parents mentioned for desiring a family based lottery focused on the convenience involved with transporting all of their children to the same school and preserving family unity by avoiding the tough decision associated with sending their children to multiple schools. ${ }^{87}$

\section{E3. Summary}

Evidence from existing research suggests that choice works best when: (1) parents have a range of high quality options to choose from; and (2) when their children, particularly middle and high school ages, are actively involved in the decision making process. The options available to OSP families varied significantly based on the grade level of the student. In addition, families participating in the OSP had to factor the lottery into their decision-making. Several parents noted that they did not inform their children about the OSP until after they knew definitively that they had been selected in the lottery. In most cases, though the parents remembered being very excited about the prospects of winning the lottery, they were reluctant to engage their children for fear that losing the lottery would be a major source of disappointment for the family.

\footnotetext{
${ }^{84}$ PSV Focus Group, Parents of High School Students, Winter 2004

${ }^{85}$ PSV Focus Group, Parents of Middle School Students, Spring 2005.

${ }^{86}$ PSV Focus Group, Parents of High School Students, Winter 2004.

${ }^{87}$ WSF reported that families expressed mixed opinions on the concept of a lottery by family. WSF commented that although a family lottery would increase the scholarship take up rate, it was not part of the original legislation and it would be difficult to match entire families with the limited number of slots available.
} 


\section{F1. What are the Components of the New Private School Environment?}

For parents who previously sent their children to neighborhood public schools, the new environment of private schools can represent a significant change. In one of the most comprehensive evaluations of inner-city school choice programs to date, Howell and his colleagues found that the parents of students who used scholarships to switch from public to private schools reported that their new schools were somewhat less likely to have a cafeteria, library, nurse's office, counselors, and special programs for non-English speakers or students with disabilities. However, the private schools were more likely to offer after-school programs and individual tutors, to enroll far fewer students and provide smaller class sizes than the typical public school. ${ }^{88}$ Private schools are well-known for offering challenging curricula and assigning more nightly homework than public schools. ${ }^{89}$ Parent and student reports have suggested that private schools are more likely to require school uniforms, practice strict discipline, and include religious activities and instruction in the school day. ${ }^{90}$

Some previous reports on school choice have suggested that extracurricular activities, such as more or better sports teams, are a strong motive for parents seeking school choice. ${ }^{91}$ There remains little evidence beyond the occasional anecdote to support such claims. The urban private schools that most scholarship students attend may, in fact, offer fewer extracurricular activities than the public schools the students left.

\section{F2. Parent and Student Voices on the New School Environment}

\section{a. Resources and facilities}

A few students expressed particular dissatisfaction with the state of facilities at their new school, while other students commented that the private schools were well maintained, though certainly not extravagant. ${ }^{92}$ A few students stated that their school had poorly maintained bathrooms, deteriorating structures, insect infestation, or poor air circulation. Examples of statements made by students included the following:

Student: I want ya'll to see our bathrooms and the...like big holes and stuff in the walls. ${ }^{93}$

Student: In the summer they leave all the doors open when it's hot and in the winter... it be so freezing, I mean you can barely teach in there. ${ }^{94}$

\footnotetext{
${ }^{88}$ Howell at al, The Education Gap..., pp. 94-102.

${ }^{89}$ Patrick J. Wolf and Daniel S. Hoople, "Looking Inside the Black Box: What School Factors Explain Voucher Gains in Washington, D.C.?” Peabody Journal of Education, 81, forthcoming in 2006.

${ }^{90}$ Ibid., especially p. 134.

${ }^{91}$ Carnegie Foundation for the Advancement of Teaching, School Choice: A Special Report (Princeton, NJ: 1992), p. 13.

${ }_{92}$ Presently, no one is responsible for holding schools accountable for complying with local codes. WSF reported that they do not have the authority to inspect facilities. For the most part, it is assumed that participating schools are in compliance with DC law pertaining to issues such as cleanliness and safety. WSF indicated that they could not exclude a school from the OSP based on the condition of their facilities unless they were in violation of applicable laws. However, WSF reported that they would take action if a potentially dangerous condition or safety issue was brought to their attention.

${ }^{93}$ PSV Focus Group, Middle School Students, Spring 2005.
} 


\section{b. $\quad$ New curriculum and increased workload}

In certain cases, parents applauded the specific curriculum in their child's new school:

Parent: $\quad$ The Failure Free Reading Program they have at [my daughter's school]. She's in that and it's like a tutoring session... She goes two or three times a week... When she was at DC public school she didn't like reading, now she loves it. ${ }^{95}$

Parents and students both felt that the curriculum in their new school was more challenging:

Parent: It's a little challenging and that's the way I want it 'cause they seem to breeze through DC public schools. ${ }^{96}$

Parent: The teacher is excellent, the intensity of the curriculum they have at her school is excellent; they have these pre-K kids doing fractions. ${ }^{97}$

Along with a more challenging curriculum came a heavier workload. One parent commented that she was worried "because it was a lot of work. I was afraid that with so many things to do she would get sick." 98

Although some students initially struggled with the curriculum and increased workload, several parents noted that it was important that the standards not be lowered to accommodate their children who were behind entering the new school or who were struggling with the adjustment process:

Parent: I just don't think there are any circumstances under which anyone's curriculum or standards should be lowered to accommodate [our children]. ${ }^{99}$

Parent: $\quad$ Our kids need to come up, we don't need to bring our standards down, our kids need to come up. ${ }^{100}$

This statement reflected the parents' view that their children should be challenged to compete with other students versus attempts or efforts to modify the curriculum and standards to accommodate OSP students. They expressed an expectation that their children would go through an adjustment period and that each child would handle it differently.

\footnotetext{
${ }^{94}$ PSV Focus Group, Middle School Students, Spring 2005.

${ }^{95}$ PSV Focus Group, Parents of Middle School Students, Spring 2005.

${ }^{96}$ PSV Focus Group, Parents of Middle School Students, Winter 2004.

${ }^{97}$ PSV Focus Group, Parents of Elementary School Students, Spring 2005.

${ }^{98}$ PSV Focus Group, Parents of Hispanic Students, Winter 2004.

${ }^{99}$ PSV Focus Group, Parents of Middle School Students, Spring 2005.

${ }^{100}$ PSV Focus Group, Parents of High School Students, Spring 2005.
} 


\section{c. $\quad$ Student discipline}

Some parents noted that the standards of discipline varied between the public and private schools. In particular, the private schools expected students to act with greater respect toward teachers and other students and to follow a more strict code of conduct. As a whole, parents appreciated the increased student discipline standards. One parent associated the new discipline standards with a noticeable improvement in their children's behavior outside of school:

Parent: When he was in a public school, he would get home and he would be violent. So then he told me that other boys got into fights among each other during the breaks... when he entered the private school though, he changed. ${ }^{101}$

While the majority of parents appeared satisfied with the strict discipline in their child's new school, others expressed mild concern. In most of these cases, however, their discomfort stemmed from the methods of discipline rather than the idea of discipline itself. A few parents also mentioned instances where their child was having difficulty adjusting to the new disciplinary standards:

Parent: $\quad$ My first grader... she got suspended Friday, three days, cause she hit a child back. Now in her school last year, they said fight 'em back... and this year it's different. I teach her at home you can't hit back, but last year that's all she was taught at school, to hit back. That's their rules but they should have a little more tolerance to know that these kids come from different backgrounds; you have to work with them.102

The following comment reflected the general sentiment of the parents.

Parent: Their learning, their conduct, they are more disciplined. Their moral values are being reinforced as well, so we are more than grateful. ${ }^{103}$

\section{d. Extracurricular activities}

It appears that the range of activities offered by the private schools varied widely. In some cases, students discovered that their new schools provided more activities:

Student: $\quad$ At my old school all they had was cheerleading and at my new school I just have lots of sports. ${ }^{104}$

\footnotetext{
${ }^{101}$ PSV Focus Group, Parents of Hispanic Students, Spring 2005.

${ }^{102}$ PSV Focus Group, Parents of High School Students, Winter 2004.

${ }^{103}$ PSV Focus Group, Parents of Hispanic Students, Spring 2005.

${ }^{104}$ PSV Focus Group, Middle School Students, Spring 2005.
} 
Other students, however, found far fewer activities in their new schools:

Student: The only thing we do at my new school is we raise money to like help the Tsunami stuff and for people that's poor we raise money to help them and stuff like that. But other than that we don't do like activities. ${ }^{105}$

A few parents also indicated that they would like to see more physical activities in their children's schools:

Parent: $\quad$ That would be very important too, an activities program. It is important for the mental and physical health of the kids; they are going to perform better. ${ }^{106}$

\section{F3. Summary}

Parents and students paint a complex picture of their new private schools. Some students complained of poorly maintained facilities. Both students and parents generally reported more challenging schoolwork that is pushing the students to the limits of their abilities. They report stricter discipline, which they generally applaud. The families spoke of great variation in both the type and amount of extracurricular activities offered at their new private schools.

\section{G1. How Do Parents Respond to New Challenges?}

Previous research suggests that private schools of choice tend to differ from public schools in more than just facilities, curriculum, discipline, and extracurricular activities. Private schools tend to require more parental involvement in educational tasks, both within the school itself and at home, assisting with homework and monitoring the more frequent schoolhome communications. ${ }^{107}$ Researchers commonly view this as a positive feature of private schools. Schneider and his colleagues contend that "education is a good that requires 'coproduction' between school personnel and parents. By increasing parental involvement, choice can create the conditions for improved school performance. "108 Although the extra involvement may be burdensome, Godwin and Kemerer conclude from their research that most educational consumers are prepared for such requirements, as "choosing parents tended to be aggressively involved in their child's education.'"

Parents of choice students face additional challenges in helping their children succeed. Wells reported that the parents of students who initially tried school choice but then returned to neighborhood schools "were frequently involved in the initial choice of a suburban school but less involved in helping their children cope in the new setting." 110 Yet, Schneider and his colleagues point out that the increased parental involvement required when schools are chosen by parents presents a great opportunity in addition to challenges. School choice can bring

\footnotetext{
105 PSV Focus Group, Middle School Students, Spring 2005.

${ }^{106}$ PSV Focus Group, Parents of Hispanic Students, Spring 2005.

${ }^{107}$ For examples, see Howell et al, The Education Gap...; Anthony Bryk, Peter B. Holland, and Valerie Lee, Catholic Schools and the Common Good (Cambridge, MA: Harvard University Press, 1993).

${ }^{108}$ Schneider et al, Choosing Schools..., p. 10.

${ }^{109}$ R. Kenneth Godwin and Frank R. Kemerer, School Choice Tradeoffs..., p. 38.

${ }^{110}$ Wells, “African-American Students' View of School Choice...," p. 32.
} 
parents who are highly motivated or have specific preferences out of the woodwork and in touch with one another in freely-chosen schools, increasing parental involvement and consequently school performance. ${ }^{111}$

\section{G2. Parent Voices on Responses to New Challenges}

\section{a. Parental involvement in child's education}

The majority of parents reported that they were more involved in their child's education as a result of the OSP. Most parents seemed to welcome the increased interaction and communication with teachers.

A few parents acknowledged that the new school requires a significant time commitment. Several elementary school parents, in particular, indicated that they were volunteering at their children's schools and working with teachers to ease their child's transition to their new school. One parent described her beliefs about parent involvement:

Parent: One has to be constantly talking to teachers, either at a public or private school, because I think that the problem of public schools is not language or anything like that but the lack of parents' will power for getting involved in their kid's life and for getting together to solve the problems. ${ }^{112}$

Most parents also agreed that supporting the teachers' efforts and the school's rules helps reinforce consistent standards between home and school. For instance:

Parent: I feel our role is supporting the teacher and also...meeting teachers, find out you know what she's teaching...the relationship between your child...But if there's a problem, you and the teacher talk you know aside from the child, so supporting what they're doing and let there be consistency between home and school. ${ }^{113}$ education:

One parent explained why she felt compelled to increase her involvement with her child's

Parent: I take responsibility for them not doing exactly what they should, it's more diligence that is required on my part. ${ }^{114}$

Most parents felt that the new schools encouraged greater parental involvement, but several parents expressed discomfort with a school's "closed campus policy" that required appointments to enter the classroom or building. Following is one parent's account of what she perceives as an inconvenient school policy:

\footnotetext{
${ }^{111}$ Schneider et al, Choosing Schools..., p. 12.

112 PSV Focus Group, Parents of Hispanic Students, Winter 2004.

${ }^{113}$ PSV Focus Group, Parents of High School Students, Winter 2004.

${ }^{114}$ PSV Focus Group, Parents of Middle School Students, Spring 2005.
} 
Parent: $\quad$ They have a closed campus policy, when I had the kids in public schools I was at the school every week talking to the teachers cause they had open door policies so that's kind of shutting me down and putting me in an area that's very conflicting with my schedule. ${ }^{115}$

Although parents were happy to volunteer at their children's schools and typically did not have trouble meeting the time requirements, one working parent explained why it was difficult to schedule and attend parent teacher conferences:

Parent: I be working in the daytime, excuse me, and they want to have a meeting with the teachers in the daytime and I can't get out my job every time they call and set up an appointment. ${ }^{116}$

Nonetheless, as a whole, parental involvement appeared to increase noticeably for the PSV parents. ${ }^{117}$ This parent's comment reflects the sentiment of many parents:

Parent: I get involved because I believe that is what is needed in the community. ${ }^{118}$

Though parents reported interaction with their children and teachers to be higher, the parents had mixed levels of involvement or participation in formal activities like the school parent organizations. Some parents reported being active in parent organizations (POs):

Parent: In the public school you couldn't get this many people with 400 children you couldn't get this many to a PTA meeting. ${ }^{119}$

On the other hand, most parents indicated that they were not very active in school based POs. Those who were not active in POs expressed a variety of reasons. Many said that they were too busy or that the POs demanded too much of their time and financial resources. A few parents, for example, expressed sentiments closely mirroring this statement from one elementary school parent:

Parent: You put your all into it and they [members of the PO] want you to put more and more and more. And I don't think that's right. ${ }^{120}$

In summary, most of the parents appeared willing to participate in informal activities like meeting with the teachers, and supporting their children's development by assisting them with homework and encouraging them to succeed:

\footnotetext{
${ }^{115}$ PSV Focus Group, Parents of Elementary School Students, Spring 2005.

${ }^{116}$ PSV Focus Group, Parents of High School Students, Spring 2005.

${ }^{117}$ School administrators also noted that OSP parents were actively involved; and acknowledged that a higher level of parental involvement is required by private schools. Despite a general increase in parental involvement among OSP families, a few administrators still felt that the parents of scholarship students needed to become more involved.

${ }^{118}$ PSV Focus Group, Parents of Hispanic Students, Winter 2004.

${ }^{119}$ PSV Focus Group, Parents of High School Students, Winter 2004.

${ }^{120}$ PSV Focus Group, Parents of Elementary School Students, Spring 2005.
} 
Parent: You have to be a part of your kid's life and sometimes it makes it harder 'cause they're stricter than the public school and there are more demands, you still have to be a part of the kid's life. Go to the school. Go to the meetings. Don't just throw your kid there and say that they have a scholarship so everything is okay. ${ }^{121}$

\section{b. Parental challenges beyond involvement in school}

Many parents faced significant challenges with the transition, including juggling work and family schedules to help their children with homework and to participate in school activities, meeting additional financial obligations, developing a relationship with teachers, and overcoming language barriers.

Unlike the students, the parents were not very forthcoming about their personal challenges and adjustments during the fall focus group discussions. ${ }^{122}$ They did, however, become more open and vocal about this matter during the spring focus groups. For example, Hispanic parents expressed the need to make adjustments because of language barriers:

Parent: $\quad$ For us there was a significant change more than anything because we were forced to go to English school to learn English... when I realized all the homework was in English, so I had to stay awake all night with a translator and a dictionary. ${ }^{123}$

Parent: Our role is to try to be informed, to get education for ourselves, so as to understand [our children's] reality. ${ }^{124}$

Several parents whose children experienced difficulty with the academic curriculum and demanding workload shared their strategies and techniques to help their children succeed:

Parent: I got me a little black and white book and each day she goes to all her classes and I have the teacher to sign it and write down if they had homework... and when you bring me your homework I have to sign it and then it goes back to the teacher so that way you kind of like keep up on what she's doing or he's doing and it will help you out. ${ }^{125}$

Parent: I tightened up on them, you can't play games, and have taken certain privileges away from them unless they do their work.... ${ }^{126}$

\footnotetext{
${ }^{121}$ PSV Focus Group, Parents of High School Students, Spring 2005.

${ }^{122}$ Questions pertaining to their own experiences with adjustment were the most sensitive topic. We suspect that, among other adjustments, parents were feeling their way through the focus group discussions. It may take us another year or two to reach a level of comfort and trust that will allow the parents to speak more openly about their more intimate experiences with OSP.

${ }^{123}$ PSV Focus Group, Parents of Hispanic Students, Spring 2005.

${ }^{124}$ PSV Focus Group, Parents of Hispanic Students, Winter 2004.

${ }^{125}$ PSV Focus Group, Parents of Middle School Students, Spring 2005.

${ }^{126}$ PSV Focus Group, Parents of Middle School Students, Spring 2005.
} 
Although parents focused more on their children's needs for support services, they did express a desire for parent counseling services. Counseling, however, was usually suggested as a resource for other parents, not themselves.

School administrators and representatives from WSF echoed the need for additional resources. School administrators reported that the OSP families could benefit from additional services, such as transportation, summer programs, and in some instances, counseling. Representatives from WSF also reported that OSP families need "wrap around" services. In particular, WSF stressed the importance of providing families with easy access to transportation for their children. ${ }^{127}$

Most prevalent among the parents' requests for support services was an organization of scholarship parents with whom they could share information and experiences:

Parent: I think that the Scholarship Program should form an alliance and maybe get some phone numbers and you know you have these focus groups and it's a shame that you leave from these focus groups and you don't remember the parents that are in here. You discuss the problems amongst each other. ${ }^{128}$

Several parents felt that the formation of a parent organization would facilitate information sharing and would allow them to come together and better address problems in their individual schools:

Parent: I'd like to meet with other scholarship parents I think we need to be unified. ${ }^{129}$

Parent: If we as scholarship parents become as one, a strong unit maybe... if we share numbers with each other everybody in here can give a piece of some ingredient to make the cake whole. ${ }^{130}$

WSF acknowledged that many of the parents in the OSP felt isolated and would like to meet with other parents who have children in the program. As discussed above, on its own initiative, WSF established a monthly parent empowerment group in the spring of 2005 to provide parents with camaraderie and give them an opportunity to discuss their experiences, concerns, and to resolve programmatic issues. It is interesting that many parents were less interested in the established school parent organizations and more interested in a new, programwide parent organization customized to their particular interests and needs.

\footnotetext{
${ }^{127}$ They found that providing families with subway access passes was an easy way for families to access transportation without having to pay anything out of pocket. WSF also felt that the availability of free lunches was extremely important for OSP families because most of them were eligible for and received free and reduced lunch prior to the OSP.

${ }^{128}$ PSV Focus Group, Parents of High School Students, Spring 2005.

${ }^{129}$ PSV Focus Group, Parents of High School Students, Spring 2005.

${ }^{130}$ PSV Focus Group, Parents of High School Students, Spring 2005.
} 


\section{G3. Summary}

Considering the potential differences between public and private schools, it is no surprise that OSP parents faced adjustment challenges in the Program's inaugural year. Dialogue from the parent focus groups upheld many of the observations cited in the school choice literature. Most OSP parents, for example, became more active in their child's education both at home and in the schools their child attends. While some found the greater time commitment to be a challenge, most seemed prepared for the increased demand as Godwin and Kemerer would have predicted. In response to higher academic standards and increased student workloads, parents usually adjusted their behavior, though at times they felt that the schools needed to be more accommodating of their schedules. Additionally, parents desired a network of OSP parents with whom they could exchange experiences and seek support, apart from the school-based parental organizations already in existence. The WSF has established just such an organization in response to the demands of its clients.

\section{H1. Student-School Responses to New Challenges}

We might reasonably expect that the different expectations and requirements in the private school sector likely require some measure of adjustment for students and educators as well as parents. Although previous research on "school choice adjustment" is quite sparse, the few studies that exist suggest that adjustment is more difficult for older students, that the quality and classroom approaches of teachers in choice schools tend to improve over time, and that the mutual adjustment of families to schools and schools to families is more likely to be successful the longer choice students remain in a school. ${ }^{131}$

Sociologist Amy Stuart Wells has written extensively about the adjustment challenges faced by students who switch from inner-city public schools to suburban schools of choice. She points out that low-income students are active participants in their educational environment, at times resisting the change expectations that are placed on them by others. ${ }^{132}$ She noted that students who transferred to a choice school at an earlier age were more likely to embrace the culture of their new school and remain in their suburban school of choice.

Another important finding from Wells' study is the possibility that transfer students might be singled out as a group and stigmatized at their new schools. Such school practices quite naturally caused the transfer students to feel alienated from their new school environment. ${ }^{133}$ On the other hand, Godwin and Kemerer reported in their study of the San Antonio scholarship program that, "no [scholarship] parents whom we interviewed indicated their child was uncomfortable in the private schools or that their child lacked friends there. In addition, there was no evidence that a teacher had encouraged a family to take a child out of the private school." 134

\footnotetext{
${ }^{131}$ Wolf, Howell, and Peterson, "School Choice in Washington, DC..."; Eric A. Hanushek and Steven G. Rifkin, "Does Public School Competition Affect Teacher Quality," in The Economics of School Choice, edited by Caroline M. Hoxby (Chicago: University of Chicago Press, 2003); Fred M. Neumann et al, School Instructional Program Coherence: Benefits and Challenges (Chicago: Consortium on Chicago School Research, 2001).

${ }^{132}$ Wells, "African-American Students' View of School Choice...," p. 26.

${ }^{133}$ Ibid., p. 37.

${ }^{134}$ Godwin and Kemerer, School Choice Tradeoffs..., p. 41.
} 
The issue of parents banding together in their schools of choice, a reasonable and appealing coping mechanism, poses an interesting dilemma for families new to school choice. As Fuller and his colleagues observe, "many parents in pluralistic America seem to want both assimilation [through high-quality schools] and particularistic forms of socialization [through schools that accommodate their special needs and values]. "135 To the extent that scholarship parents call attention to the special needs of them and their children, they might risk stigmatization and disrupt the full assimilation of their children into their new school. To the extent that they remain quiet about their family's special needs, they may prevent the new school from responding to those needs in constructive ways.

\section{H2. Parent and Student Voices on Student-School Responses to New Challenges a. Student adjustments and attitudes regarding learning}

Some students acknowledged that encouragement and active participation by their parents was extremely important to their academic success:

Student: $\quad$ My mom she helps me with my homework. She encourages me to keep trying and do my best like when I was doing the Stanford 9 and stuff like that she cut off the TV and stuff. I couldn't talk on the phone so I just stayed in my room all day studying and trying to improve. ${ }^{136}$

The majority of parents reported positive improvements in their child's attitude toward academics and learning, and their confidence level. These are some of the observations parents made:

Parent: She's able to get up and she's confident in herself that she can do it and that's one big thing that to me that was excellent. ${ }^{137}$

Parent: He has acknowledged, with the acquisition of this scholarship and by knowing the reason behind this scholarship, a great responsibility. ${ }^{138}$

One parent also commented on the distinct change she noticed in her daughter's overall attitude:

Parent: $\quad$ I have to say that my daughter, her whole attitude has changed...I'll bring her to work with me and even my co-workers have commented on how much she has changed...the way she walks and talks, and how she interacts with other children. It's much different than when she was going to public or charter school. ${ }^{139}$

\footnotetext{
${ }^{135}$ Fuller et al, "Policy Making in the Dark...," p. 13.

${ }^{136}$ PSV Focus Group, Middle School Students, Spring 2005.

${ }^{137}$ PSV Focus Group, Parents of Elementary School Students, Spring 2005.

${ }^{138}$ PSV Focus Group, Parents of Hispanic Students, Spring 2005.

${ }^{139}$ PSV Focus Group, Parents of Middle School Students, Spring 2005.
} 


\section{b. $\quad$ Tutoring and mentoring}

As mentioned previously, in response to the heavy workload, parents and students were unanimous in their belief that tutoring and mentoring services would help ease the transition of OSP students into private schools. Some parents whose children are currently receiving these services praised their schools for providing tutoring services to students:

Parent: [My child's high school] is really great and they have tutors and you gotta let them know what you need and they'll set them up with either a student tutor or a teacher. ${ }^{140}$

On the whole, parents appreciated the tutoring programs available to their children, but they offered several suggestions for improving them. Parents recommended that tutors be available in both the first and second half of the school year (rather than tutoring primarily in the first half); that tutoring be aligned with classroom instruction; and that tutors receive more training:

Parent: I asked [the teacher] if he had met with the tutors and if they were in line with what he was working with the kids on, so they can just supplement what he was going. He didn't have a clue, he hadn't met them, the gap there was no bridge. It wasn't like they had met with the teachers to find out what the standards were and what they were working on. ${ }^{141}$

Parent: $\quad$ The [school] has college students doing the tutoring and I'm just concerned about whether or not they are really qualified to tutor the children. ${ }^{142}$

Some students added that they primarily rely on their families for support, but would like to have mentors available to them in the schools. When asked what kind of support would be useful, students replied:

Student: I would say mentors 'cause...she help me with everything, science, math, everything I need and that improved my grades. This year I don't have a mentor and it's kinda hard. ${ }^{143}$

The students' desire for a mentoring program was also motivated by the need for exposure to peer role models who could perhaps better understand and relate to them. One middle school student described the type of mentoring program he envisioned:

Student: $\quad$ Something for after school that could be like for free and then they take you on different trips and it's like a big brother big sister thing and you feel comfortable around them. ${ }^{144}$

\footnotetext{
${ }^{140}$ PSV Focus Group, Parents of High School Students, Spring 2005.

${ }^{141}$ PSV Focus Group, Parents of Middle School Students, Spring 2005.

${ }^{142}$ PSV Focus Group, Parents of Middle School Students, Spring 2005.

${ }^{143}$ PSV Focus Group, Middle School Students, Winter 2004.

${ }^{144}$ PSV Focus Group, Middle School Students, Spring 2005.
} 
The majority of school administrators believed that student support services, such as tutoring, mentoring, and counseling, provide a solid foundation for learning. Many administrators felt that the scholarship students' needs were no different from other students at their schools and that the support services already in place at their school were adequate. They went on to note that providing OSP families with separate services could cause them to feel singled-out.

WSF also recognized the importance of providing OSP students with access to tutors. WSF pointed out it was beyond the scope of their responsibilities to provide students with tutors, but they would like to see more schools establish in-house tutoring services. WSF does have a partnership with Capital Partners for Education (CPE) for high school students in the OSP to receive mentoring, tutoring, and academic counseling throughout the year, on a voluntary basis. WSF noted that tutoring expenses must be approved by the schools and in line with the financial policies and procedures already in place at the school. Families cannot use scholarship money to obtain tutoring services on their own. WSF commented that families were often unaware and frustrated that tutoring fees consumed a significant portion of their scholarship.

\section{c. Student educational aspirations}

Students were nearly unanimous in their desire to attend college. They consistently expressed their belief that the opportunity to attend private schools will help them reach this goal:

Student: $\quad$ People will look at you different if you come from the public schools. Say, like in the future when you go to college, people will look at you like on your resume or whatever...they look at the public school and they think that's a bad school, but if it's on a private school, they think it's a better school and you've got a better chance of making it. ${ }^{145}$

Although students complained about tougher classes, they reported being especially happy with the environment of their new schools.

\section{d. Effect of scholarship students on school culture}

Administrators at participating schools were asked if the culture of their schools were affected in any way by the introduction and presence of OSP students. Ten out of the eleven administrators interviewed reported either no cultural change, or a strictly positive effect. One administrator reported that the culture of their school was negatively affected by the disciplinary problems of OSP students when they first entered school in the fall. She went on to note that veteran students helped alleviate the problem by setting an example of how to act in accordance with the school's code of conduct.

Administrators who reported that the OSP students had a positive effect on the school mentioned cases in which the OSP students became an intrinsic part of the community, enriched the school with diversity, and broadened sensitivity.

${ }^{145}$ PSV Focus Group, Parents of High School Students, Spring 2005. 


\section{e. School receptivity to participating families}

There were varying interpretations of the level of welcome that students and families received at private schools in the DC Opportunity Scholarship Program. Some families felt embraced by the private school teachers, the school administration, and the surrounding community:

Parent: The parents embraced her during the summer before school started so she had a chance to meet other kids that were going to be in the $4^{\text {th }}$ grade class which made that much better.

Parent: It's like the people there treat me like I'm a part of their family. The school is just so family-oriented. I mean I am so happy. ${ }^{146}$

When asked whether they felt "singled out" by participating in the Program, responses were again mixed. Most families indicated that they did not feel stigmatized. Even when required to sign their scholarship check, parents indicated that they did not feel different from other parents. One parent described an encounter with a school administrative who informed her that:

Parent: 'Your check is in the rectory [administrative office] please go sign it'- nothing at school, you know it's a different building. People are going in and out of the building all day so it's not like you're pinpointed. ${ }^{147}$

This experience, however, was not universal. A number of parents and students felt "singled out." These feelings arose in some cases based on perceived, and in other cases explicit, words or actions by teachers. In one instance, when a teacher did single out a student and the parents brought it to the attention of the administration, the parent reported that the matter was quickly solved:

Parent: When she first got there...she was having a little bit of adjustment problems and the teacher told her in front of the classroom, if you don't stop acting like this, remember, you are here on a scholarship and we could put you out...I spoke with the principal and things were handled. ${ }^{148}$

A few parents described their discomfort and wondered if they were stigmatized because of their affiliation with the OSP:

Parent: Sometimes I wonder if there's not some sort of stigma attached to the children that receive the scholarship. ${ }^{149}$

\footnotetext{
${ }^{146}$ PSV Focus Group, Parents of Middle School Students, Winter 2004.

${ }^{147}$ PSV Focus Group, Parents of High School Students, Spring 2005.

${ }_{148}$ PSV Focus Group, Parents of High School Students, Spring 2005.

${ }^{149}$ PSV Focus Group, Parents of Middle School Students, Spring 2005.
} 
Parent: I really do think there's a stigma attached to the children receiving scholarship funds... 150

Some parents thought that non-OSP parents and school administrators perceived them as "non-working" or "needy." One parent noted the following:

Parent: Unfortunately they seem to think that you don't care. We have a lot of parents that don't seem to care about their children. They're going to think that you're one of them and unless you put your foot down. ${ }^{151}$

The students' experiences were much different than their parents. High school students, for example, did not express any comments that suggested they were being "singled out" or stigmatized. Many of them felt that remaining anonymous helped them avoid being singled out. Following is one student's comment:

Student: If you let them know, that's when you get treated differently. If you don't, if you act like everybody else, then they won't know. ${ }^{152}$

Parents unanimously asserted that every effort should be made to protect their families' confidentiality:

Parent: Whenever schools decide to participate in having people come to their program it should strictly be stipulated that whoever is coming in and out of this program it's supposed to be confidential. ${ }^{153}$

Parent: I don't think it should be the teacher's business and I don't think it should go past the office meaning that it should be the principal and the secretary who knows that you get a scholarship. ${ }^{154}$

School administrators also asserted that participation in the OSP should be kept confidential. Many of the administrators who were interviewed reported that the identities of their scholarship students were only known by the administration. ${ }^{155}$

The parents reported mixed experiences with admissions counselors. One parent noted how the admissions counselors were kind and considerate:

\footnotetext{
${ }^{150}$ PSV Focus Group, Parents of Middle School Students, Spring 2005.

${ }^{151}$ PSV Focus Group, Parents of Middle School Students, Spring 2005.

${ }^{152}$ PSV Focus Group, Parents of Hispanic Students, Spring 2005.

${ }^{153}$ PSV Focus Group, Parents of Middle School Students, Spring 2005.

154 PSV Focus Group, Parents of High School Students, Spring 2005.

${ }^{155}$ WSF officials were taken by surprise by the reports of students being singled out by teachers for their participation in the OSP, particularly because WSF verbally discussed the confidentiality issue with participating schools. WSF stated that if a breach of confidentiality was brought to their attention, they would have directly contacted the school. For the 2005-2006 school year, WSF inserted a confidentiality clause into the school agreements.
} 
Parent: I spoke to the admissions officer and she told me you don't have to worry about anything just to get her to be tested and then if the tests come out ... she was very kind and encouraging. ${ }^{156}$

Parent: I went to open houses and things like that. I got a different level of respect but then when I moved to another phase and mentioned after you have a one-on-one and talk about how you're going to discuss this paying the bill, mentioning the scholarship fund, I'm going to be honest my first feeling I think it changed a lot of her possibilities of getting into the school. ${ }^{157}$

In some cases, scholarship parents felt unwelcome not by the school personnel, but by parents whose children were not receiving scholarships:

Parent: There is elitism in the parent organization 'cause I went to a meeting and I was pointed out some issues and a parent just said - why don't you leave. ${ }^{158}$

Some scholarship parents felt that other parents would become more comfortable as the Program progressed: ${ }^{159}$

Parent: $\quad$ They are used to seeing diverse people yes but not low-income people.

Therefore, I believe that parents, more than anyone else, are getting used to the idea that the school has more diversity than before. ${ }^{160}$

In most cases, parents did not indicate that they were disheartened by any perceived partiality for or against OSP families. In fact, when asked whether they think the situation will improve or not, parents felt overwhelmingly that the level of comfort between families receiving scholarships and teachers, administrators, and other parents would likely improve as the OSP continues to evolve. As one parent noted:

Parent: I think...as the years go by ...there will be more experience. They will know better how to deal with us and we will be more comfortable. ${ }^{161}$

\section{H3. Summary}

The range of student views were of a slightly to a distinctly different learning environment in their new schools. Facilities, extracurricular activities, disciplinary standards, school culture and levels of receptivity were among the most frequently mentioned differences. Most of the parents and students acknowledged that the private schools practiced stricter discipline standards than their children's previous schools. In several cases, parents observed a notable improvement in their children's behavior due to the higher level of discipline. Parents and students expressed mixed responses concerning the receptiveness of private schools to OSP

\footnotetext{
${ }^{156}$ PSV Focus Group, Parents of High School Students, Spring 2005.

${ }^{157}$ PSV Focus Group, Parents of High School Students, Spring 2005.

${ }^{158}$ PSV Focus Group, Parents of Middle School Students, Spring 2005.

${ }^{159}$ WSF confirmed that families appeared to be more comfortable with the program as it progressed

${ }^{160}$ PSV Focus Group, Parents of Hispanic Students, Spring 2005.

${ }^{161}$ PSV Focus Group, Parents of High School Students, Spring 2005.
} 
recipients and their families. Some parents and students felt the schools welcomed them, while others shared instances were they felt they were singled out or were treated differently.

Notwithstanding the mixed reviews on receptivity, the families were not discouraged and, in fact, predicted that their relationships with the schools will improve over time.

\section{I1. How Does Finance and Reimbursement Policy Impact Choice Programs?}

The implementation of timely and transparent finance and reimbursement policy will be an important determinant of success for an educational choice program. While research on this particular element of consumer behavior is limited in the field of education, findings from other areas are more readily available. Using micro-simulation models, Gruber and Levitt find that easing liquidity constraints (by offering ongoing versus annual subsidies) would increase takeup of new health insurance coverage by 34 percent. ${ }^{162}$ Such a finding is not surprising. Particularly among low-income families, many are unable or unwilling to devote scarce resources to purchase goods or services when reimbursement is not certain in the near future. Similarly, we expect delays or failures in reimbursement to decrease the take-up and continued use of educational scholarships unless issues are addressed in a timely manner.

Simplicity of reimbursement and transparency of cost will also affect voucher take-up and public perception of the program. Longitudinal data over a cross-section of states suggests that voters tend to be more willing to devote resources to government programs that practice greater financial transparency. ${ }^{163}$ Given the sharp divide over whether public monies should be used to subsidize private $K-12$ education, parents and the public will likely require a reasonable level of transparency regarding where and how scholarship funds are being spent, if the program is to continue receiving support. Additionally, the process for reimbursing out-ofpocket expenditures by parents will need to be as simple as possible. A somewhat parallel situation can be found in the goods market with mail-in rebates. Based on reviews of academic and business literature, Silk and Janiszewski argue that increasing the complexity and required effort of consumer rebates decreases product purchase and rebate redemption. ${ }^{164}$ Likewise, difficult-to-navigate reimbursement policies will increase transactional costs for educational consumers leading to greater frustrations among participants, and ultimately lower usage

\section{I2. Parent and Student Voices on Financial and Reimbursement Policy}

The greatest source of frustrations expressed by parents centered on financial issues. Many parents felt that the financial policies of the OSP initially lacked clarity with regards to costs covered by the scholarships and reimbursement procedures. To further complicate matters, several parents believed that participating schools were disseminating inconsistent reimbursement information. For instance, one parent mentioned that they were confronted with unexpected expenses:

\footnotetext{
162 Jonathan Gruber and Larry Levitt, "Tax Subsidies for Health Insurance: Costs and Benefits" Health Affairs (19:1) 2000.

${ }^{163}$ James E. Alt, David Dreyer Lassen, and David Skilling, "Fiscal Transparency, Gubernatorial Popularity, and the Scale of Government: Evidence from the States Economic Policy Research Unit (EPRU) Report 2001-16, 2001.

${ }^{164}$ Tim Silk and Chris Janiszewski, "Factors Responsible for Non-Redemption and Breakage of Mail-in Rebate Offers: Pre-Purchase, Post-Purchase, and Repeat-Purchase Factors” Working Paper. Journal of Marketing.
} 
Parent: I was told you're supposed to be reimbursed for some of the things you purchase out your own pockets. 165

Parents also reported instances in which ancillary fees, additional costs, and mandatory "donations" placed a heavy burden on them financially:

Parent: We are really having financial constraints right now just because we have to pay for the lunch program, we have to pay additional for the uniform... the school is a high standards school so like they told us to come up with a new complete suit, like would cost over 200, 300 dollars. ${ }^{166}$

Parent: I was told I needed to pay $\$ 250$ to show that we are committed. ${ }^{167}$

While a number of parents felt that the OSP made clear what costs were covered, others felt the use of scholarship money needed to be better clarified. The parents recommended that a universal reimbursement procedure be instituted for the OSP. ${ }^{168}$ Some Hispanic parents also sought an alternative option to fundraising events and felt obliged to participate if the Opportunity Scholarship did not cover all the costs and the school had to pay part of tuition.

Some of the administrators we interviewed echoed these concerns. One school administrator relayed that they created an account, which enabled parents to purchase uniforms directly without having to use their own money and file a reimbursement claim. Subsequently, WSF sent a letter to all schools recommending that they set up school accounts with uniform vendors, so that uniforms could be paid for directly by the school using scholarship funds.

WSF asserted that schools should consult with and inform parents of their charges prior to submitting the bill to WSF. WSF currently sends OSP families a detailed payment report each time that it receives a bill and issues payment to an OSP student's school. Through the course of the first year, WSF has reported a number of steps taken to clarify and improve the process of informing parents and schools about financial policies and handling reimbursements. ${ }^{169}$ If a parent has a legitimate complaint about a financial issue, WSF expressed a willingness to call the school on the parent's behalf and attempt to resolve the issue.

\footnotetext{
${ }^{165}$ PSV Focus Group, Parents of Middle School Students, Spring 2005.

${ }^{166}$ PSV Focus Group, Parents of Hispanic Students, Winter 2004.

${ }^{167}$ PSV Focus Group, Parents of High School Students, Winter 2004.

${ }^{168}$ WSF specified that parents who have complaints should first try to work the problem out directly with the school. If the issue cannot be resolved, WSF will call the school on behalf of the parent and try to work through the problem.

${ }^{169}$ Initially, WSF communicated the financial procedures and policy to the parents through a series of letters and telephone conversations. In the fall of 2004, WSF prepared and sent a "fee process explanation" to all participating schools. WSF supplemented this explanation with additional letters to help clarify issues as they arose. In the spring of 2005, WSF produced a one-page document for the parents that outlined the costs covered under the scholarship. In the fall of 2005, WSF published a manual for participating schools that clearly sets forth costs covered, billing processes, and all financial procedures. WSF also facilitated the billing process for schools by establishing a new online billing system. WSF reported that it specifically recommended that schools avoid making parents pay for expenses covered by the scholarship out of pocket. For parents who do pay for education expenses out of pocket, WSF stressed the importance of first checking with the school to confirm that the expense will be covered by the scholarship.
} 


\section{I3. Summary}

The development of financial policies and procedures has been constantly evolving and improving throughout the Program. Some initial confusion surrounding the finance issues clearly impacted the families. These issues, at times, dominated the focus group discussions.

WSF has tried to clarify their policies to make it easier for both families and schools to understand how the financial and reimbursement procedures work. Some parents had benefited from these improvements and readily offered advice to other parents about the financial policies during the spring focus groups.

\section{J1. Are Students and Parents Satisfied with School Choice?}

How satisfied do parents tend to be with the new schools that their scholarship children attend? Virtually every school choice program evaluated to date has reported very high levels of parental satisfaction with choice schools, especially in the initial year of their experiences with choice. ${ }^{170}$ Satisfaction with the new schools of choice may be higher initially either because the dissatisfaction with their previous schools is freshest at that point, or because the charms of the new schools has a tendency to wear off somewhat over time, as parents become more aware of the shortcomings in their schools of choice. Satisfaction with choice schools also may vary by the level of schooling, as Godwin and Kemerer report that students were more likely to dropout of the CEO Horizon program in San Antonio when transitioning from middle to high school. ${ }^{171}$

\section{J2. Parent and Student Voices on Satisfaction and Most Memorable Experiences}

Students were generally satisfied with their new schools and felt that the atmosphere in their private schools was an improvement over their previous experiences. They credited several aspects of their new schools - improved safety, religious instruction, and a different curriculum - to their positive experience. For example, several high school students cited college prep courses as a major source of their satisfaction. Overall, students felt their new school would provide them with more options for the future. Most of them agreed with the following statement made by a high school student:

Student: It's just more opportunity than public school, I guess that's why ya'll call it the Opportunity Scholarship. ${ }^{172}$

One student made the following statement regarding their current school:

Student: $\quad$ You don't have to worry about nobody bringing guns or knives to school. ${ }^{173}$

\footnotetext{
${ }^{170}$ For examples see Howell et al, The Education Gap, pp. 168-184; John Witte, The Market Approach to Education (Princeton, NJ: Princeton University Press, 2000).

${ }^{171}$ Godwin and Kemerer, School Choice Tradeoffs..., p. 40.

172 PSV Focus Group, High School Students, Spring 2005.

${ }^{173}$ PSV Focus Group, Middle School Students, Spring 2005.
} 
A small number of parents noted instances in which the new school's religious environment reinforced the values they instill in their children at home:

Parent: $\quad$ Religion for us was very important because that helps for the culture of the child. They come and tell me: "Today we attended Mass, we participated, today the Pope was elected, we were happy." Things like that do not happen in a public school. ${ }^{174}$

Student: I like that my school teaches me about the Bible and God, I go to a Christian school. $^{175}$

Parents expressed comfort and satisfaction with religious-based education, their perception of improved education and safety, and the increase in parental involvement.

By the spring of 2005, the majority of parents reported that they think their children are performing better in school:

Parent: $\quad$ Mine are doing a lot better, academically. ${ }^{176}$

Parent: As a mother, one feels very proud of seeing them learn because probably in a public school, she wouldn't be as advanced as I see her now. That is why I felt happy to see the change in just months. ${ }^{177}$

Parents also felt that their children were expressing greater enthusiasm for school and that they expended more effort:

Parent: $\quad$ Every night she does her homework no matter how many papers she has to do she does it. ${ }^{178}$

In certain cases, however, parents indicated that their child's academic performance had not improved, or, in a few instances, had declined. These parents attributed the stagnation or decline in performance to the adjustment process or higher standards than those that existed previously:

Parent: Their grades are not as good since they've been going to this school. Their workload is a lot more challenging... ${ }^{179}$

As an indirect way to solicit feedback about their new educational reality, focus group participants were asked to share their most memorable experiences in the OSP. Parents and students replied with a mix of positive and negative responses.

\footnotetext{
${ }^{174}$ PSV Focus Group, Parents of Hispanic Students, Spring 2005.

175 PSV Focus Group, Middle School Students, Winter 2004.

${ }^{176}$ PSV Focus Group, Parents of Elementary School Students, Spring 2005.

${ }^{177}$ PSV Focus Group, Parents of Hispanic Students, Spring 2005.

178 PSV Focus Group, Parents of Middle School Students, Spring 2005.

${ }^{179}$ PSV Focus Group, Parents of Middle School Students, Spring 2005.
} 
The group of parents whose most memorable moments were negative most often focused on a particular difficulty with a school administrator or teacher rather than characteristics of the school itself:

Parent: $\quad$ But the principal, we can't even communicate, it's like oil and water and it's not only with me, with other scholarship parents as well. ${ }^{180}$

Parent: They [the children] had the teacher leave the first, the beginning of the year. The other teacher they had was really nice. She would sit down and explain the homework to them, you know, what they needed to do, the other teacher she just says - do the work. ${ }^{181}$

In other cases, parents and students identified a lack of facilities or services including playground equipment, tutoring, and in-school activities. The students' main source of discomfort was the school uniforms.

Although parents expressed general satisfaction with the OSP, a few indicated that they would like to transfer their children to different schools within the OSP. These parents focused at length on the factors that led to their original school choice decisions. Parents questioned many factors that initially influenced their decisions concerning the choice of schools, including the availability of accurate information; the level of participation in the school fairs; the amount of school visits made by the family; the experience or lack thereof of parents in choosing schools; and the relationship between their child and the teachers. Most of these parents indicated that they would invest more time and energy into visiting the schools and making a more careful decision in the future. ${ }^{182}$

Parents felt that WSF or some other entity should give more information about the process to change schools and the available seats in other schools:

Parent: $\quad$ They should give more information about the process for parents who want to change schools, if there is room in other schools because the last time there was this problem. We didn't get the school that we chose; we got the one that we chose in the last place.... So now if we are changing schools we are going to fight for those same rooms. ${ }^{183}$

Parents displayed excitement about the new opportunities that their children had to learn and express themselves. One elementary school parent mentioned that her daughter was now participating in school performances that were not available at her prior school. Another parent mentioned her child's exposure to foreign language in class. The typical positive response ${ }^{184}$,

\footnotetext{
${ }^{180}$ PSV Focus Group, Parents of Elementary School Students, Spring 2005.

${ }^{181}$ PSV Focus Group, Parents of Middle School Students, Spring 2005.

${ }^{182}$ A WSF official confirmed the importance of investing an adequate amount of time and energy into the search process. The official informally noticed that the parents who put more effort into the search were happier with the results.

${ }^{183}$ PSV Focus Group, Parents of Hispanic Students, Spring 2005.

${ }^{184}$ School Administrators also expressed widespread satisfaction with the OSP. They wish it could be expanded to include families with slightly higher incomes, and they want to see it continue as a permanent, rather than just five-
} 
however, was one of general excitement felt by both the students and parents, as summed up in the following statement:

Parent: When my son dressed in that uniform with that green blazer, the white shirt, tie, gray trousers and he looked like a gentleman and a scholar and he had his hair cut and his glasses and he was just grinning from ear to ear that he was going to be a part of that [new school culture] and he went to school that day and he was excited about going to school. ${ }^{185}$

\section{J3. Summary}

Similar to other choice programs, parents and students of the OSP expressed generally high levels of satisfaction with both their schools and the Program during the inaugural year. For satisfied participants, no single thread could be found connecting each family, although a few common themes included safety, smaller class sizes, and exposure to religious-based education. Although most parents said that they think their children are performing better academically, that important question will be best assessed in the rigorous experimental impact study of the OSP currently underway outside of this qualitative study.

By the spring, a few parents and students became more willing to share sources of dissatisfaction with the participating schools, which may have been an effect of becoming more comfortable and knowledgeable with the Program or the focus group facilitators, or that the excitement of receiving a scholarship and beginning at a new school had slightly worn off. Sources of dissatisfaction centered mostly on particular disagreements with staff or teachers, although some parents also expressed concern that their child was not learning as much as they should, or was not adjusting fully to their new surroundings.

Even for those parents dissatisfied with their school selection, satisfaction with the Program overall remained quite high. While parents offered suggestions for improving program administration, none definitively indicated that they would remove their child from the OSP. Parents and students most often cited the opportunities that the Program created as the main reason for their satisfaction.

year program. A few Administrators also felt that raising the value of the opportunity scholarship would make the program more accessible and valuable. At some schools, the $\$ 7,500$ scholarship covers less than $40 \%$ of tuition and the school has to come up with the additional financial aid to cover OSP students' tuition. A few administrators suggested that a higher value scholarship would encourage more schools to participate in the OSP.

${ }^{185}$ PSV Focus Group, Parents of High School Students, Spring 2005. 


\section{THE NEXT STEPS}

We have learned some valuable lessons that will guide the planning and organizing for year two of the PSV study. As the first year research process unfolded from gathering, to organizing, to analyzing and ultimately presenting the data, the research team was struck by the complex and sometimes conflicting nature of the school choice experience as expressed by the participating families. This report begins a discussion about school choice that attempts to tell a story about how 45 families experienced the first federally funded school voucher program.

The first year of the PSV study has only scratched the surface of the rich complexity inherent within the school choice debate. In the previous sections, we summarized some of the existing research on school choice to help the reader better understand and conceptualize discrete aspects of school choice from a demand side perspective. However, our primary objective was to glean information from the focus groups that allowed us to juxtapose the popular literature against PSV participants' first year in the OSP.

Our research revealed the difficulty of pinpointing where distinct elements of consumer behavior or communitarian activities begin and where they end. For example, during the focus groups, the parents discussed their involvement with school choice from four subtle, but profoundly different, perspectives: (1) how they learned about the OSP; (2) what motivated them to pursue OSP; (3) what factors they considered as they weighed the pros and cons of this opportunity; and, ultimately, (4) what factors influenced their final decision to participate. These are all similar, yet different, variations of one aspect of school choice - how do parents decide. However, the popular research on this subject does not acknowledge the complexity involved with new families' experiences with school choice.

Moreover, we would argue that parental roles and responsibilities vary with regard to each discrete aspect of the school choice process, and that the very process is, in fact, cyclical. Given that student and parent experiences with schools is an annual process that families will complete and repeat again until their children leave the OSP or graduate from school, the families' experiences must be understood and assessed over time. As the National Working Commission on Choice in K-12 Education observed in their recent report, "When choice is first introduced, parent preferences are likely to be less clear and predictable than they might be after parents have had time to make choices and observe the consequences."186 Jeffrey Henig further justifies the use of a longitudinal assessment of family perspectives when he concludes that:

"Making a social policy work means adjusting the original conception to local circumstances. It means investing in it the resources and effort needed to give it a chance to succeed. It means monitoring feedback, and responding to new information and changing conditions...it means exercising the patience to wait for results without abandoning the effort prematurely.",187

\footnotetext{
${ }^{186}$ Report from the National Working Commission on Choice in K-12 Education, Paul T. Hill (Chair), (Washington: Brookings, 2003), p. 26.

${ }^{187}$ Henig, Rethinking School Choice..., p.220.
} 
We share Henig's point of view and therefore seek to continue our chronicle of PSV on the DC Opportunity Scholarship Program over the full five years of its proposed trial implementation.

It should be noted that our greatest source of confidence in a longitudinal study stems directly from the exceptional levels of participation by the families who volunteered for this study. Not only have they participated in an extensive set of activities for a study of this type, they have expressed sincere interest in making sure that the public at large understands their experiences. Thus, as we continue to strengthen our relationships with them, we look forward to further exploring some of the topics highlighted above, as well as other topics that emerge from their experiences with the OSP. 


\section{APPENDICES}

\section{A. Research Approach}

\section{General overview}

In an attempt to expand our knowledge about the impact of the OSP on the participating families, the SCDP proposed complementing the government-funded quantitative analysis with a qualitative study. Parent and Study Voices on the DC Opportunity Scholarship Program seeks to provide an extremely rare view of the implementation and impact of a publicly funded school voucher program from the vantage point of the first year participants. The primary goal of the study was to chronicle the experiences of the inaugural families. In addition and when possible, the study allowed the participating families to provide their personal insights on and recommendations about critical features of the OSP.

This qualitative study focused on 60 families, representing approximately 100 students that were awarded scholarships for the first year of OSP. An equal number of families with (1) elementary, (2) middle and (3) high school age students, as well as a special focus group for (4) Spanish speaking families, were invited to participate in two sets of focus groups that were hosted in December 2004 and April 2005. While the parents and other caregivers convened in their designated groups, middle and high school age students, respectively, met in separate focus group sessions.

The numbers and percentages of various groups of invited parents who participated in the focus groups are displayed in Table 1. Table 2 shows the numbers and types of students who participated. In both the fall and spring focus groups, participation rates were lowest among Hispanic parents and increased successively through the grade levels with high school parents displaying the highest participation rates.

Table 1. Number and Type of Participants per Parent Focus Group

\begin{tabular}{|l|c|c|c|c|c|c|c|}
\hline \multicolumn{2}{|c|}{} & \multicolumn{3}{c|}{ Fall 2004 } & \multicolumn{3}{c|}{ Spring 2005 } \\
\hline & $\begin{array}{c}\text { \# of } \\
\text { Volunteers }\end{array}$ & $\begin{array}{l}\text { Total } \\
\text { Invited }^{\mathrm{a}}\end{array}$ & $\begin{array}{l}\text { Total } \\
\text { Parts. }\end{array}$ & $\begin{array}{l}\text { Part. } \\
\text { Rate }^{\mathrm{b}}\end{array}$ & $\begin{array}{l}\text { Total } \\
\text { Invited }\end{array}$ & $\begin{array}{l}\text { Total } \\
\text { Parts. }\end{array}$ & $\begin{array}{l}\text { Part. } \\
\text { Rate }^{\text {b }}\end{array}$ \\
\hline Hispanic & & 12 & 4 & $33 \%$ & 14 & 7 & $50 \%$ \\
\hline Elementary School & & 17 & 10 & $59 \%$ & 17 & 11 & $65 \%$ \\
\hline Middle School & & 19 & 12 & $63 \%$ & 17 & 11 & $65 \%$ \\
\hline High School & & 17 & 13 & $77 \%$ & 18 & 14 & $78 \%$ \\
\hline Total & $\mathbf{2 3 0}^{\text {c }}$ & $\mathbf{6 5}$ & $\mathbf{3 9}$ & $\mathbf{6 0 \%}$ & $\mathbf{6 6}$ & $\mathbf{4 3}$ & $\mathbf{6 5 \%}$ \\
\hline
\end{tabular}

${ }^{\mathrm{a}}$ Invitations went out to a total of 60 parents. In households with two parents, both parents were welcomed to participate. In rare instances, both parents participated in the focus groups.

${ }^{\mathrm{b}}$ Participation rate equals total participants divided by the number invited.

c Since volunteer families could belong to multiple categories, we only assigned them to a specific category once they were selected to be invited 


\section{Table 2. Grade Level of Participants per Student Focus Group}

\begin{tabular}{|l|c|c|}
\hline Grade Level & Fall 2004 & Spring 2005 \\
\hline Middle School & 10 & 13 \\
\hline High School & 11 & 10 \\
\hline Total & $\mathbf{2 1}$ & $\mathbf{2 3}$ \\
\hline
\end{tabular}

The number of children per family of those attending the focus groups is displayed in Table 3. The average number of household children in both sets of focus groups closely approximated the average for all OSP families obtained from the official government evaluation. $^{188}$

Table 3. Focus Group Families by Number of Household Children

\begin{tabular}{|l|c|c|c|c|}
\hline & \multicolumn{2}{|c|}{ Winter 2004 } & \multicolumn{2}{c|}{ Spring 2005 } \\
\hline \# of children & $N$ & $\%$ & $N$ & $\%$ \\
\hline 1 & 6 & 17 & 7 & 19 \\
\hline 2 & 12 & 34 & 12 & 32 \\
\hline 3 & 10 & 29 & 11 & 30 \\
\hline 4 & 2 & 6 & 3 & 8 \\
\hline $5+$ & 5 & 14 & 4 & 11 \\
\hline Valid $\boldsymbol{N}$ & $\mathbf{3 5}$ & & $\mathbf{3 7}$ & \\
\hline & & & & \\
\hline Average (PSV Study) & 2.80 & & 2.70 & \\
\hline Average (Total OSP) & 2.83 & & 2.83 & \\
\hline
\end{tabular}

Figures 1 and 2 on the following page display the attendance of focus group participants by ward. Ward participation was evenly distributed with the exception of Wards 2 and 3 . This is not surprising, however, given that these wards include many of the higher-income areas of Northwest DC and would likely house fewer participating OSP families.

${ }^{188}$ Wolf et al, Evaluation of the DC Opportunity Scholarship Program..., p. D-7. 
Figure 1. Fall 2004 Focus Group Participation by Ward

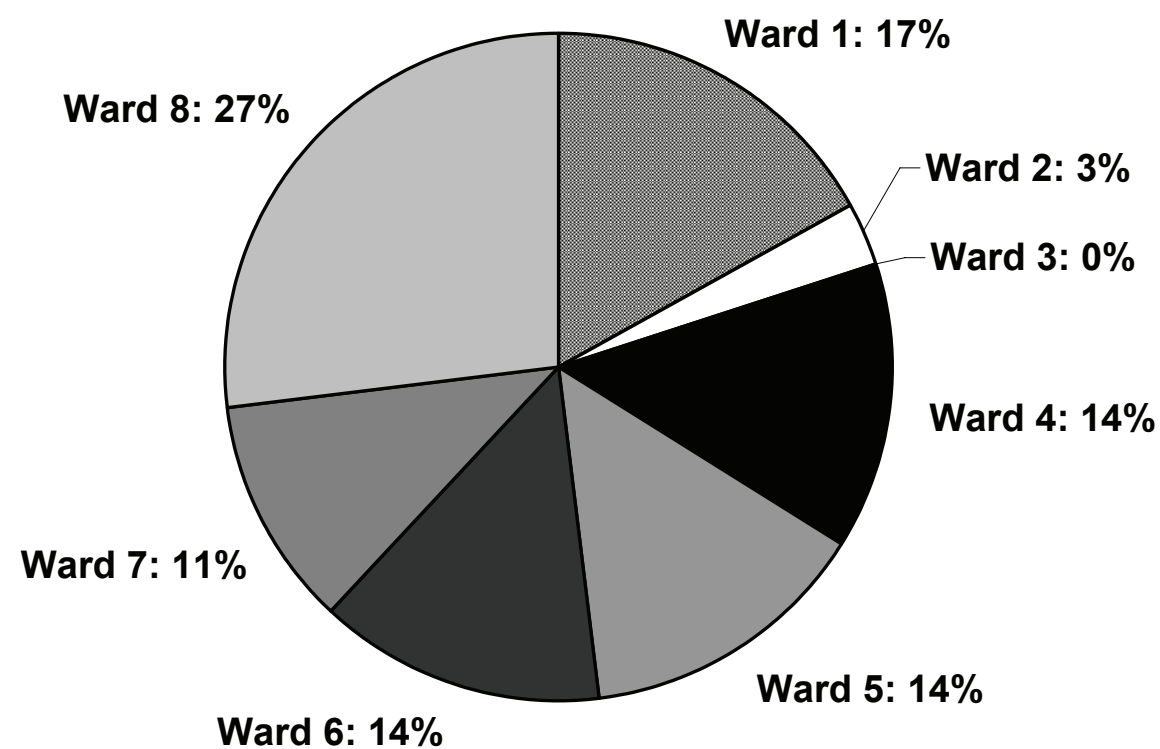

Note: Percents may not add to 100 due to rounding.

Figure 2. Spring 2005 Focus Group Participation by Ward

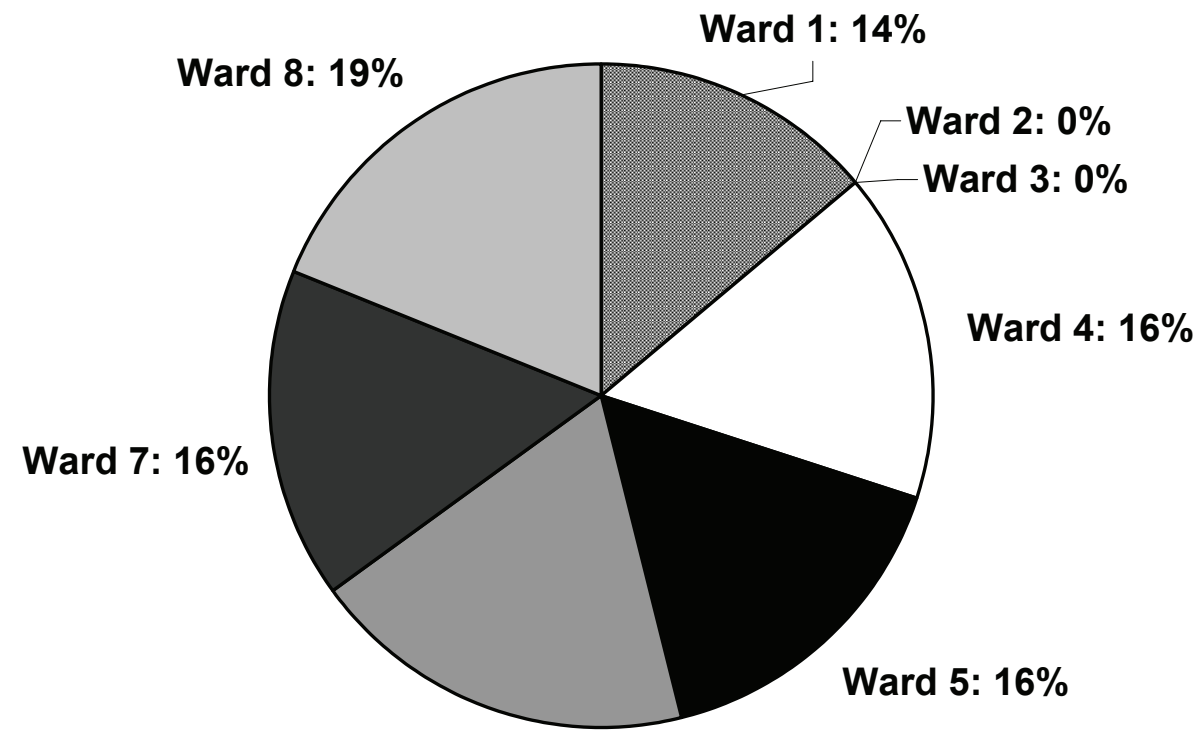

Ward 6: $19 \%$

Note: Percents may not add to 100 due to rounding. 
In addition to the conversation with the students and parents, we conducted brief telephone interviews with representatives ${ }^{189}$ of 11 randomly selected schools participating in the Program during the first year. In total, the eleven schools interviewed account for 316 of the 1,027 Opportunity Scholarship Recipients in 2004. We also conducted a personal interview with several staff members from the Washington Scholarship Fund.

Table 4 displays some general characteristics of the 11 schools that were randomly selected for administrator interviews. Compared to all schools participating in the OSP, our sample of administrators is fairly representative in regard to religious affiliation and tuition. The list of administrators selected for this study over-represented schools serving the high school grades and the elite private schools, but only by a slight margin. Thus, the views of the school administrators discussed in the text are expected to be representative of most participating schools, though there certainly is no guarantee that is the case given the small number of interviewees.

${ }^{189}$ Administrators interviewed included Principals or Headmasters and Assistant Principals. 
Table 4. Characteristics of Schools Interviewed

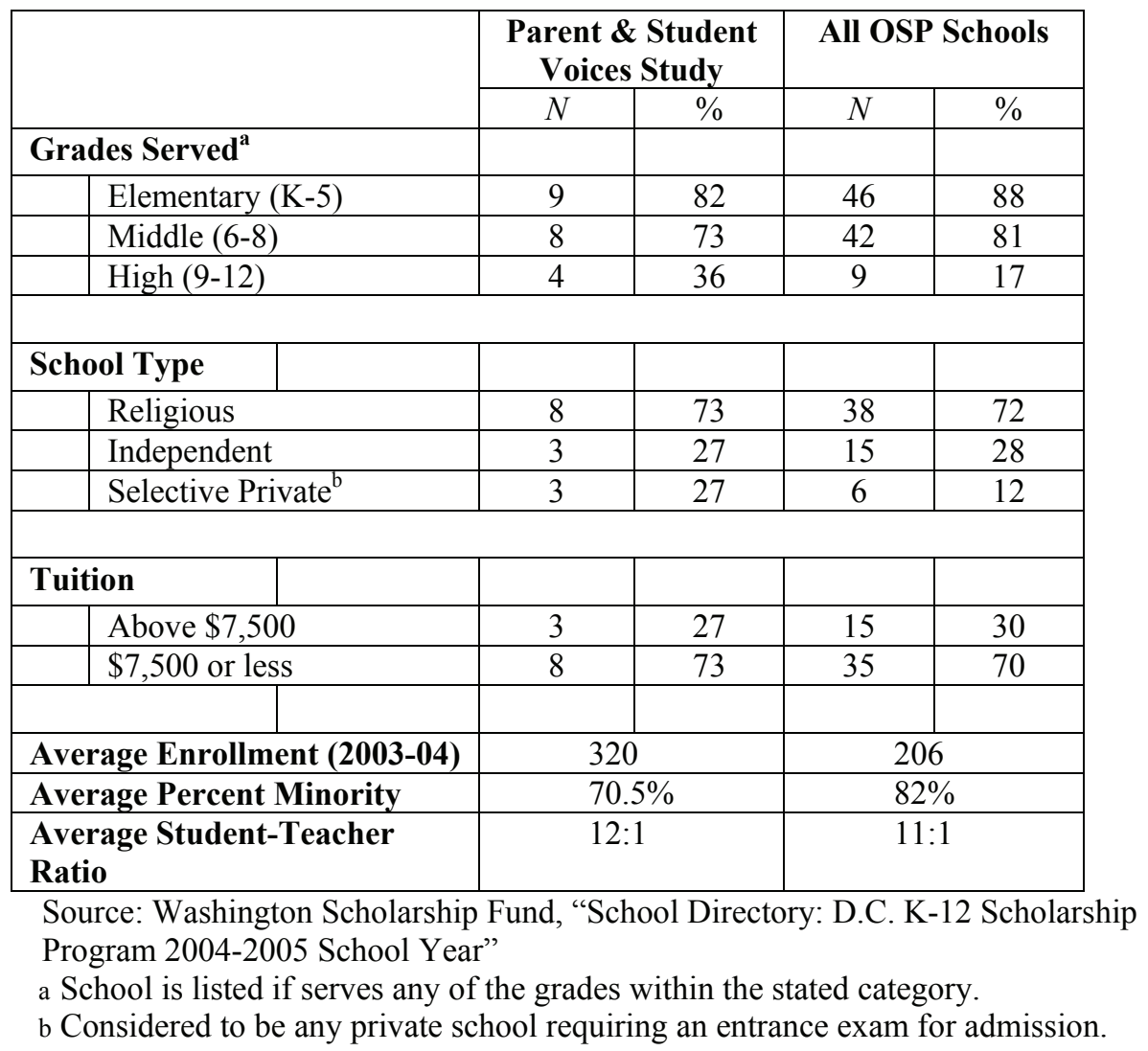

Our initial research proposal predicted that approximately $10-20 \%$ of the families selected for this study would leave the Program in the first year. Thus, in addition to the focus groups, we were prepared to conduct "personal exit telephone interviews" with each family that leaves OSP. It should be noted that none of the 60 families selected for this study left OSP in the first year. ${ }^{190}$ Therefore, no exit interviews were conducted.

The ultimate goal is to conduct a five-year longitudinal study that will convene the participating families twice a year (winter and spring) from 2004-2009. Our specific objectives for the first year included:

Build trust and rapport with the participating families;

Solicit information that will act as a baseline for the longitudinal study; and

\footnotetext{
${ }^{190}$ The fact that no focus-group families left the program in the first year is probably due to two factors. First, the Washington Scholarship Fund experienced very little within-year program attrition, losing less than 5 percent of their scholarship users during the initial school year. Second, the families who volunteered to participate in our study, and attended focus group sessions, are probably a more enthusiastic and committed sub-group of all participant families.
} 
Document and describe the experiences of the participating families with the goals of contributing to the existing scholarship on school choice and raising the awareness of the public at large about this important social issue.

\section{Outreach to parents}

The OSP requires families to renew their scholarship each academic year. During the initial renewal meetings in November 2004, members of the SCDP research team were allowed to provide the families an overview of the study and extend them an invitation to participate. It was noted that the study would offer participants a chance to inform other parents, school administrators, policy makers, and others who are interested in understanding the effects of a school choice program. The prospective participants were informed about how this aspect of the evaluation differs from the test and survey activities required of them under the official program evaluation, highlighting the fact that it will require an additional time commitment. They were also told that their involvement with the study would be entirely voluntary at all times and that the information they provided would be kept confidential. Moreover, they were told that their decision would have no impact on whether or not their children were able to renew their scholarship or gain admission to a preferred school. Families that expressed an interest in participating in the study were given a short informational form to complete, which requested their names, address and other general contact information, as well as a consent form to participate in research.

A total of 230 families volunteered to participate in the Family Perspectives study. Based on the grade level of the students and the primary language spoken within each family, they were placed in one of the four categories - families with student in elementary, middle and high school, as well as a special category for Spanish speaking families. Approximately 60 families were randomly selected from the pool of candidates who specifically volunteered for the Family Perspectives study, including roughly 60 parents or other caregivers and 30 students in middle or high school. The families received letters inviting them to attend one of six focus group events held in December 2004. The letters emphasized that the focus groups would provide families an important opportunity to help improve the scholarship program by sharing their insights and experiences.

In situations in which confirmation phone calls indicated that attendance at the Family Perspectives focus groups would be lower than originally intended, additional invites were made to bring the number of focus group participants up to a more desirable level. These "add-ons" were most commonly the spouse of another parent attending the focus group or a volunteer drawn at random from the original list.

Families were contacted in advance to discern time and dates that would be convenient. The meetings were hosted at convenient and central locations. Because the meetings were held on either weekday evenings or weekend afternoons, food and childcare were provided. Students and parents were given gift certificates as a small token of appreciation for participating.

It should be noted that the participants in this study are not necessarily representative of all District families or even all families participating in the OSP. The families that applied to the 
Program, especially in the initial year, are likely more motivated to seek an educational alternative for their children than are typical DC parents. In addition, scholarship families who attended the renewal meeting and volunteered for the study are not necessarily representative of all families participating in the OSP. For starters, families who did not plan to renew their scholarships, whether for reasons of dissatisfaction or outside circumstances such as a move, were naturally not present at the renewal meeting. In addition, the willingness of our respondents to volunteer to participate in our Family Perspectives study may indicate that they differ from typical program participants in any number of ways. Families who volunteered presumably felt that the opportunity to share their insight and experiences with Program implementers and the broader public was worth the time and effort it took to attend the focus group sessions. Thus, it is possible that these parents possessed stronger opinions and or experiences, either positive or negative, that they were more involved in and aware of their children's education, or that they were more capable, because of transportation methods or time availability, of attending the focus groups.

Thus, because participants were chosen from a group of volunteers, readers should exercise caution in interpreting the material in this report as being truly representative of the Program as a whole. The opinions and experiences expressed here are those of a modest number of volunteer families, and may not reflect the general experiences of families program-wide. Nevertheless, the responses that we chronicle are authentic statements of Program parents, and shed light on how a particular group of families are experiencing our country's first federally sponsored K-12 scholarship program.

\section{Conversations with families, school administrators and WSF officials}

Focus groups were conducted with both parents and students and were professionally facilitated using the same set of questions across each grouping of parents and students. Parent focus groups were divided into four sections representing: 1) parents of elementary school students, 2) parents of middle school students, 3) parents of high school students, and 4) parents of Hispanic students of all ages. ${ }^{191}$ Student focus groups were limited to middle school students and high school students because it was felt that the elementary schools students were too young to participate and the students of Hispanic parents were able to participate in the English-spoken student focus groups.

At the beginning of each focus group session, participants were assured of their anonymity and were asked to provide candid and open responses to the questions. Group facilitators prompted the discussion with probing questions and encouraged active discussion by all members (see Appendix B for a complete schedule of questions). The questions were designed to allow the participants to reflect upon critical features of their experience ranging from how they heard about the OSP to application and school selection processes to their most memorable first year experiences. The facilitators were given the latitude to probe for relevant details associated with the general comments. Focus groups lasted approximately two hours and were tape recorded and transcribed for accuracy.

\footnotetext{
${ }^{191}$ A separate group for Hispanics was added so as to include scholarship families with Spanish speaking parents.
} 
In addition to the conversations with parents, interviews with school administrators and WSF were used to solicit information that would give us an alternative perspective on many of the topics. This information allowed us to verify and validate many of the responses made by the families. For example, we asked the parents what resources or support services could help them be more successful. We asked the school representatives and staff from WSF, in their opinion, what resources could help the families be more successful. We asked the school representatives about their awareness of OSP students within their school, their perception of the OSP in general, and how the Program has affected their particular school. In most cases, their comments appear in the footnotes.

\section{Data Analysis}

During the actual focus groups, we provided students and parents with opportunities to discuss their experiences from three time dimensions: past, current and future. The focus groups questions were broad in scope, allowing each participant ample opportunity to contribute to the discussion. As noted above, there were six sets of focus groups that met in both the fall and spring.

Once they were completed, the transcripts for each focus group were analyzed by members of the research team, specifically teasing out the salient and varied responses within each group. After each individual researcher completed a chart of topical responses, they meet with a partner, who had independently charted the same focus group transcript, to discuss their observations and consolidate their summaries into a "team chart." Once the "team charts" were completed, the entire research team met to compare and contrast the findings across the four parent groups, the two students groups, and eventually the parents and students.

The text of the report reflects an attempt to provide a descriptive overview of the comments made by the parents and students. When possible, the research team provided a more detailed account of the topics that the respondents were willing to discuss at greater length.

\section{External peer review}

Our initial draft of the final report was sent to four outside reviewers for comments. The peer reviewers were selected based on their expertise on the topic of how families experience school choice and the diversity of their views regarding the general desirability of expanding choice. The authors attempted to incorporate most of the peer reviewer suggestions into the final version of the report. 


\section{Key activities and timeline}

Table 5 provides a general overview of the key activities completion time associated with the first year of the PSV study.

Table 5. Year 1 Project Timeline

\begin{tabular}{|l|l|}
\hline Activity & Actual Completion \\
\hline Finalize Protocols & November 2004 \\
\hline Recruit Families & November 2004 \\
\hline Fall Focus Groups & December 2004 \\
\hline Transcribe Focus Groups & January 2004 \\
\hline Preliminary Report & January 2005 \\
\hline Spring Focus Groups & April 2005 \\
\hline Exit Interviews & N/A \\
\hline Transcribe Focus Groups & May 2005 \\
\hline $\begin{array}{l}\text { Interview School } \\
\text { Administrators and WSF }\end{array}$ & July 2005 \\
\hline Draft Final Report & July 2005 \\
\hline External Peer Review & August 2005 \\
\hline Release Final Report & October 2005 \\
\hline
\end{tabular}




\section{B. Focus Group Guides}

FALL PARENT FOCUS GROUP MODERATOR'S GUIDE

December 14, 2004

\section{Greetings (5 minutes)}

Good evening. My name is xxx. Thank you for coming to participate in today's focus group.

- The purpose of our group is to get your opinions about your experiences with the D.C. Opportunity Scholarship Program.

- Your thoughts will be useful in helping to improve the program.

- If you have participated in focus groups before, you know how the process works.

- We encourage you to express your views freely. There are no right or wrong answers.

- Let's discuss some of the ground rules before we begin. We will have an informal discussion during which I will ask some questions. We would like to know what each of you thinks.

- I will ask other staff in the room to introduce themselves:

- They are here to observe and take notes. All of your comments are confidential and will never be connected to you in any way. Only group results will be reported. To ensure that we get everything you are saying, an audiotape recording is being made of this session. The tape enables us to focus on having a free-flowing conversation with you and less on hand note taking. WE WILL START THE TAPE RECORDER NOW.

\section{Introductions (5 minutes)}

Ok, let's get acquainted by going around the table and introducing ourselves, giving only our first name. I will start, by saying again that my name is

\section{Focus group questions (70 minutes)}

\section{Theme 1 - Exercising Choice}

\section{Question 1}

What motivated you to apply for the DC Choice Scholarship Program?

How did you find out about the program? 
Before you learned about this program, what effort had you made to pursue other education options for your child(ren)?

\section{Question 2}

What did you look for in selecting a school for your child(ren)?

Did you involve your child in the selection process?

Who did you rely on for information about different schools?

What source of information was most helpful to you in selecting the school that your child(ren) attends?

\section{Theme 2 -Parents critique of the program and recommendations for improvement:}

\section{Question 1}

What have been the most beneficial aspects of the program thus far?

Do you feel that your child is performing better in his/her new school?

What recommendations would you make about getting the word out about this program to other parents?

\section{Question 2}

What haven't you liked about the DC Scholarship program?

Have you encountered any obstacles in participating in the program?

What, if any, are your concerns about enrolling your child in a non-public school?

What recommendations would you make to the program administrators about the program?

\section{Break - 10 minutes}

\section{Theme 3 - Understanding parent attitudes and beliefs about their different roles:}

\section{Question 1}

What role should parents have in promoting and supporting education within the home? How involved should parents be in selecting the school(s) their child attends? 


\section{Question 2}

What is the role of parents in the schools their child attends?

\section{Theme 4 - Parent support needs and advice to other parents}

\section{Question 1}

What support will you need to successfully help your child(ren) adjust to his/her new school?

How satisfied are you with the amount of information that you are receiving from your child's private school?

What advice would you give parents like you who might be interested in the scholarship program?

\section{Question 2}

At this point, do you think your child will remain in his/her new school for the rest of the year?

How important is your child's experience with his/her new school to your decision to keep them in the program?

What recommendations would you make about getting the word out about this program to other parents?

\section{Wrap-up and Closing (10 minutes)}

Now that you had a chance to hear one another's perspectives on the issue of parent support, what other comments or questions do you think we need to discuss this evening?

Did anyone have any final comments or questions?

Thank you all for coming today. We appreciate the time you took to sit down and share with us. Your opinions have been very informative.

\section{Total Planned Time: 90 minutes}


December 14, 2005

\section{Greetings (5 minutes)}

Good evening. My name is xxx. Thank you for coming to participate in today's focus group.

- The main reason why we are here is because we would like to hear your opinions about your experiences with the DC Opportunity Scholarship Program.

- What you tell us will help us improve the program. Your thoughts, opinions, critiques and experiences will be very useful not only for us but also to make this a better experience for you.

- If you have participated in focus groups before, you know how the process works.

- We encourage you to express your views freely. There are no right or wrong answers.

- Let's discuss some of the ground rules before we begin. We will have an informal discussion during which I will ask some questions. We would like to know what each of you thinks.

- I will ask other staff in the room to introduce themselves:

- They are here to observe and take notes. All of your comments are confidential and will not be shared with anyone. Only group results will be reported. To ensure that we get everything you are saying, an audiotape recording is being made of this session. The tape enables us to focus on having a free-flowing conversation with you and less on hand note taking. WE WILL START THE TAPE RECORDER NOW.

\section{Introductions (5 minutes)}

Ok, let's get acquainted by going around the table and introducing ourselves, giving only our first name. I will start, by saying again that my name is

\section{Focus group questions (70 minutes)}

\section{Theme 1 - Student's attitudes and beliefs about the DC Scholarship Program}

\section{Question 1}

How did you hear about the scholarship program?

What was your immediate response when you heard about it? Were you excited? 


\section{Question 2}

Were you involved in your family's final decision to make use of the scholarship?

Do you recall what convinced your parents the most to change schools/ use the scholarship program? Did you agree with your parent's decision?

\section{Theme 2 -Students' critique of their new school}

\section{Question 1}

What do you like most about your new school thus far?

\section{Question 2}

What would you change about your new school to improve your experience?

If you could bring something from your old school, (anything, teachers, the class you liked best for example) to your new school what would that be? Or what were the things that you liked best about your old school?

What role did your friends form your neighborhood play in your decision to come to this school? Do they encourage you?

\section{Break - 10 minutes}

\section{Theme 3-Students' attitudes about learning and measures of success.}

\section{Question 1}

What does doing well in school mean to you?

Why is school important to you?

How important are grades for you?

\section{Question 2}

How did you think this new school would help you to do well in the way you just defined it? Do you feel more "successful" here than in your old school? Looking back, do you think you were right, or maybe too optimistic or pessimistic? 


\section{Theme 4- Students' support needs and satisfaction}

\section{Question 1}

Who do you turn to for support when you need help for things related to school?

What kind of help do you get at home?

\section{Question 2}

At this point, do you think you will remain in your new school for the rest of the year?

If not, what do you think will be the main reasons for you to leave?

\section{Wrap-up and Closing (10 minutes)}

Now that you had a chance to hear one another's perspectives on this issue, what other comments or questions do you think we need to discuss this evening?

Did anyone have any final comments or questions?

Thank you all for coming today. We appreciate the time you took to sit down and share with us. Your opinions have been very informative.

\section{Total Planned Time: 90 minute}


April 18, 2005

\section{Greetings (5 minutes)}

Good evening. My name is xxx. Thank you for coming to participate in today's focus group.

- The purpose of this meeting is to continue the conversations we started in December. As we mentioned then, your thoughts will be useful in helping to improve the Scholarship Program.

- If you participated in the December focus groups, you know how the process works.

- We encourage you to express your views freely. There are no right or wrong answers.

- Let's discuss some of the ground rules before we begin. We will have an informal discussion during which I will ask some questions. We would like to know what each of you thinks.

- We divide the focus group into three sections:

1. 40 minutes reviewing some of the findings from the first focus group;

2. 50 minutes continuing the conversation we started during the first ; and

3. 15 minutes getting your feedback about the SCDP team.

- Ask other team members in the room to introduce themselves.

- Note that they are here to observe and take notes. All of participant comments are confidential and will never be connected to you in any way. Only group results will be reported. To ensure that we get everything you are saying, an audiotape recording is being made of this session. The tape enables us to focus on having a free-flowing conversation with you and less on hand note taking. WE WILL START THE TAPE RECORDER NOW.

\section{Reflections on the first set of focus groups (40 minutes)}

Ok, let's get reacquainted by going around the table and introducing ourselves, giving only our first name. I will start, by saying again that my name is

List the key findings from fall focus groups and solicit their opinions about them. Note that some of the findings will be presented in the final report.

- Some parents said it was too early to say if their child was doing better. What changes, if any, have parents noticed in their child's attitude about learning and their academic performance? 
- With the exception of the Spanish-speaking parents, parents did not cite any support needs. Do they have a need for any additional support services?

- Some parents expressed discomfort with the school based parent organizations. How active and comfortable are they with the parent organizations?

- Some of the students felt that their teachers were singling out scholarship recipients. Do any of the parents feel they are being singled out or treated differently from other parents/families?

\section{Dialogue II (50 minutes)}

Theme 1 - Parent Views on DC Scholarship Program:

Have your views about the Scholarship Program changed? If so, how?

What is your families' most memorable experience thus far in the Program?

Theme 2 - Parents critique of the process and recommendations for improvement:

What recommendations would you make to improve the program in general and your child's ability to succeed in particular?

Do you feel that your child is performing better in his/her new school?

Theme 3 - Understanding parent attitudes and beliefs about their different roles:

What role have you played in helping your child adjust and succeed in their new school? How has does this compared to last year?

Theme 4 - Parent support and satisfaction:

What support will you need to help your child(ren) succeed in their new school?

What help do you need?

\section{AT THIS POINT, DO YOU THINK YOUR CHILD WILL REMAIN IN HIS/HER NEW SCHOOL FOR THE REST OF THIS YEAR?}

How important is your child's experience with his/her new school to your decision to keep them in the program?

Now that you had a chance to hear one another's perspectives on the issue of parent support, what other comments or questions do you think we need to discuss this evening? 


\section{Feedback about the study (10 minutes)}

Remind them that our goal is to continue to meet with them for the next four years. As a result, we are interested in discussing what we need to do to maintain their participation.

- Best form of communication

- What is the best day of the week?

- Time of day?

- Locations

- Other suggestions for improving our interaction with them?

Did anyone have any final comments or questions?

Thank you all for coming today. We appreciate the time you took to sit down and share with us. Your opinions have been very informative.

Total Planned Time: 115 minutes 
April 20, 2005

\section{Greetings (5 minutes)}

Good evening. My name is xxx. Thank you for coming to participate in today's focus group.

- The purpose of this meeting is to continue the conversations we started in December. As we mentioned then, your thoughts will be useful in helping to improve the Scholarship Program.

- If you participated in the December focus groups, you know how the process works. We encourage you to express your views freely. There is no right or wrong answers.

- Let's discuss some of the ground rules before we begin. We will have an informal discussion during which I will ask some questions. We would like to know what each of you thinks.

- Ask other team members in the room to introduce themselves.

- Note that they are here to observe and take notes. All of participant comments are confidential and will never be connected to you in any way. Only group results will be reported. To ensure that we get everything you are saying, an audiotape recording is being made of this session. The tape enables us to focus on having a free-flowing conversation with you and less on hand note-taking. WE WILL START THE TAPE RECORDER NOW.

\section{Reflections on the first set of focus groups (40 minutes)}

Ok, let's get reacquainted by going around the table and introducing ourselves, giving only our first name. I will start, by saying again that my name is

List the key findings from fall focus groups and solicit their opinions about them. Note that some of the findings will be presented in the final report.

- Beginning singled out by teachers

- Homework and other assignments

- Support with difficult subjects

\section{Dialogue II (40)}

Theme 1 - Student views on DC Scholarship Program:

Have your views about the Scholarship Program changed? If so, how? 
What is your most memorable experience thus far in the Program?

What has been the most challenging experience you have had?

Theme 2 - Students critique of the process and recommendations for improvement:

What recommendations would you make to improve the program in general and your child's ability to succeed in particular?

Theme 3 - Understanding student attitudes and beliefs about their different roles:

How can your parents better support you?

Theme 4 - Student support and satisfaction:

What support will you need to succeed in your new school?

What help do you need?

\section{AT THIS POINT, ARE YOU INTERESTED REMAINING IN YOUR NEW SCHOOL NEXT YEAR?}

Now that you had a chance to hear one another's perspectives on the issue of parent support, what other comments or questions do you think we need to discuss this evening?

\section{Feedback about the study (10 minutes)}

Remind them that our goal is to continue to meet with them for the next four years. As a result, we are interested in discussing what we need to do to maintain their participation.

- What are the key considerations?

Did anyone have any final comments or questions?

Thank you all for coming today. We appreciate the time you took to sit down and share with us. Your opinions have been very informative.

Total Planned Time: 100 minute 
C. WSF Policies and Documents

1. WSF Systems for Ensuring Fiscal Responsibility

\author{
Washington Scholarship Fund \\ Opportunity Scholarship Program \\ Systems for Ensuring Fiscal Responsibility
}

\begin{abstract}
Pursusant to Section 5(b)(1)(G) of the D.C. Choice Incentive Act (H.R. 2556), monitors whether participating schools are financially responsible. This means that the school must:
\end{abstract}

1. Report compliant with 'Generally Accepted Accounting Principles (GAAP)."

2. Spend federal funds in a manner consistent with the statute:

a. Tuition and fees must be charged to scholarship students at the same rate as nonscholarship students, in accordance with Section 7.(a)(1) of the statute: “...the amount of any tuition or fees charged by a school... does not exceed the amount of tuition or fees that the school customarily charges to students who do not participate in the program."

b. Fees must be charged in a responsible and transparent manner

c. Pass through fees are charged at cost or with up charges that are reasonable, customary and documented.

To fulfill its statutory obligation, WSF has set the following systems in place:

1. Monitoring Fiscal Responsibility: All participating schools must submit audited financial statements and the accompanying management letter for the previous fiscal year from a licensed CPA firm stating that the school is operating in accordance with generally accepted accounting principles (GAAP). The requested audit information was detailed in the Opportunity Scholarship Program, Letter of Agreement signed by all schools as a requirement of participation in the Program. If a school feels that submitting the audit is a breach of confidentiality, the school may opt to submit the management letter only. While audited financial statements are preferred, WSF understands that not all schools will have formal audits available. In these cases, WSF will accept a signed letter from a licensed CPA that states that the school's financial systems and statements are prepared in accordance with GAAP. For this purpose, an accountant's compilation statement would be sufficient.

2. Monitoring that Tuition and Fees are billed in accordance with the law: A school that generates complaints from five or more WSF scholarship families (or more than $30 \%$ of enrolled WSF scholarship families) regarding the way tuition and/or fees are charged to the scholarship will trigger a review of its tuition and fees process and documentation. WSF requires that schools hitting this threshold provide a detailed listing of any and all school fees charged to the scholarship that amount to more than $\$ 200$ per year (if lunch is $\$ 2.50$ a day, the total would be more than $\$ 200$ per year, so lunch must be included on the list). The listing must include 
the following information for each fee: the names and address of any outside vendor(s), the amount charged to the families, and how the amount is billed to the scholarship, specifying:

a. If the cost is billed directly to WSF or is prepaid by the family and reimbursed by the school;

b. If the fee represents the actual cost (a pass through) or if there is an upcharge and the amount of that up-charge;

c. An additional copy of the school's published tuition and fees schedule (submitted at the beginning of the school year); and

d. A published tuition and fee schedule for the school's previous academic year (currently 2003-2004).

3. Enabling families to make an educated choice: A school that experiences attrition of $30 \%$ or more of matriculating students in one school year will trigger an interview process at any point during the year when this trigger threshold is reached. The interview process is designed to identify ways in which the school can communicate more effectively with applying families so that families can make better decisions about whether or not a school is a good match for them. When a student transfers, the scholarship funds must be divided between two schools which can jeopardize the ability to use the scholarship in the most effective manner possible. The result can cause out of pocket expenses for families depending on the tuition rates of the new or previous school.

\section{Working further with schools where financial complaints are linked to high} attrition rates: A school that experiences sufficient complaints regarding financial matters and these complaints are linked to an attrition rate that triggers an interview, will be required to submit to a detailed audit or a management letter that specifically addresses whether or not the school is meeting the criteria detailed above. If the school does not have a historical audit performed by a credentialed and reputable independent CPA that can aid WSF in the audit, the school must allow WSF to provide an independent CPA to perform this function - to audit the school's processes and documentation to ensure that the school is operating under the requirements of the legislation. The CPA will not be a staff member of WSF to ensure the confidentiality of the school, and will not share information with WSF that would jeopardize the confidentiality of the school or its students. The purpose of the audit is for WSF to be able to document that the school is, in the professional opinion of an independent accounting professional, solvent, adhering to the tuition and fee billing requirements and that the school is operating in a responsible and transparent manner as detailed above. 


\section{WSF "Payments and Costs Covered" Letter to the Schools}

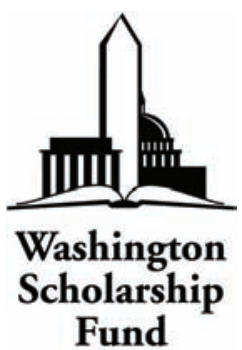

August 25, 2004

Dear School Leader,

As the school year approaches, we know you have many questions about the fee payment process. WSF has worked hard to devise a system that makes sense for the schools and the families. In this letter, we hope to frame the fee process for you in a clear and concise manner.

As you know, the D.C. K-12 Scholarship Program provides up to $\$ 7,500$ for each student for tuition, fees and transportation.

\section{How our payments will work}

Payments from WSF will be made directly to your school three times during the 2004-2005 school year. The first payment will include a portion of tuition and all pre-paid fees. The second and third payments will include portions of tuition and remaining fees. The following chart explains this process (exact dates have yet to be determined):

\begin{tabular}{|c|c|c|c|c|}
\hline Payment & Approximate Date & $\begin{array}{c}\text { Tuition } \\
\text { Included }\end{array}$ & Fees Included & Worksheet Explanation \\
\hline Payment 1 & September & $40 \%$ of Tuition & Pre-paid fees & $(.40 \times$ Line 2$)+$ Line 10 \\
\hline Payment 2 & Mid December & $30 \%$ of Tuition & $\begin{array}{c}50 \% \text { of } \\
\text { Additional Fees }\end{array}$ & $(.30 \times$ Line 2$)+(.50 \times$ Line 29$)$ \\
\hline Payment 3 & Late March & $30 \%$ of Tuition & $\begin{array}{c}\text { Remaining } \\
\text { Additional Fees }\end{array}$ & $\begin{array}{c}(.30 \times \text { Line } 2)+\text { Remaining Fees } \\
\text { from Line 29 }\end{array}$ \\
\hline
\end{tabular}

- Checks from WSF for your scholarship recipients will be made out in the parent's/guardian's name but will be sent directly to the school.

- The parent/guardian will need to visit your school to sign the checks over to you.

- The first payment will be triggered by WSF's receipt of the student's Fee Worksheet (discussed later in this document).

- The second and third payments will be triggered by WSF's receipt of each student's report card for the first and second grading period. You will receive more information on sending us report cards in the coming weeks.

- If your tuition is more than $\$ 7,500$, your payments will consist of only tuition in the above percentages. 
- The school must inform WSF immediately of any D.C. K-12 Scholarship students who have left school for any reason.

\section{Allowable fees}

Generally, any fee that corresponds with an activity, service or product that contributes to the academic success of a student is allowable. Here is a list of common allowable fees:

- $\quad$ School-year academic support (tutoring, remedial work, etc.)

- School uniforms

- $\quad$ Book fees

- School supply fees

- $\quad$ Before/After care

- $\quad$ Physical education fees

- $\quad$ Academically-oriented field trips (overnight field trips will need to be approved on a case-by-case basis)

- $\quad$ Enrichment fees (e.g., music and art programs)

- $\quad$ Library fees

- $\quad$ Laboratory fees

- Technology fees

- $\quad$ Transportation Fees

- Cafeteria Fees

- Summer academic support that is required of all students with the same academic needs

- Costs associated with required extracurricular activities (required of all students in the grade)

We expect that other miscellaneous fees will pop up from time to time. We are counting on you to keep track of these (and all) fees for each student. The school must inform WSF of any additional fee it wants covered (up to the $\$ 7,500$ cap) by submitting the information to Jennifer Brown, WSF Interim Chief Program Officer, at 202-293-5560 or jbrown@washingtonscholarshipfund.org. We will handle new fees on a case-by-case basis. WSF will decide within 21 days of receipt whether the fee in question will be allowable.

\section{Informing us of fees for each student}

As previously stated, WSF needs your school to keep track of fees incurred for (and by) each student. We have included a Fee Worksheet in this package. Please do the following:

- Make one copy of this worksheet for each student.

- Complete Page 1 of the worksheet by listing the amounts for tuition and pre-paid fees. List only the fees that you and the family want to count towards the $\$ 7,500$ cap. Once you reach $\$ 7,500$, do not list any more fees.

- If there is any money remaining under the \$7,500 cap after you have completed Page 1, then complete Page 2. Again, list only the fees that you and the family want to count towards the $\$ 7,500$ cap. Once you reach $\$ 7,500$, do not list any more fees. 
- Please work with the family to make sure that the remaining money is applied to the family's overall expenses in a way that enables the student to stay in school. WSF can not be involved in deciding which fees to count towards the $\$ 7,500$ cap.

- If there is room under the $\$ 7,500$ cap, please give priority to a family’s out-of-pocket expenses (such as uniforms) over an expense of similar worth incurred by your school.

- Fax a Fee Worksheet for each enrolled D.C. K-12 student to Ed Greenberger at (202) 293-7893 as soon as possible. The school's Principal must sign each Fee Worksheet.

- WE CAN NOT SEND PAYMENT 1 TO YOUR SCHOOL UNTIL WE RECEIVE A STUDENT'S FEE WORKSHEET! This worksheet will serve as official confirmation that the student is in attendance at your school. Please do not send us a Fee Worksheet unless the student is in attendance at your school.

- After you submit a Fee Worksheet for a student, WSF will provide that student's parent/guardian with a copy of the completed Fee Worksheet.

\section{What to tell families about out-of-pocket expenses}

This has easily been the most-asked question during the placement process. Here's what you need to know:

- Families need to give you all of their receipts for out-of-pocket expenses not paid directly to the school, such as uniforms and application/registration/enrollment fees. The families have been informed that they need to keep their receipts for these expenses.

- If there's room under the $\$ 7,500$ cap, please list these fees in the appropriate space on the Fee Worksheet and check "Yes" in the column to the right of the amount to indicate that the family paid out-of-pocket for this expense.

- Again, please give priority to a family's out-of-pocket uniform expenses.

- After the parent/guardian signs each payment check over to you, it will be up to you to reimburse the families for their out-of-pocket expenses as WSF can not reimburse families directly.

- With regard to school supplies, WSF will reimburse families only for supplies required by the school.

\section{What to tell families about transportation}

Any transportation fees that fall under the umbrella of public transportation are allowable. This includes Metro and Metro Bus service and traditional school bus service (if your school provides it). Families can pre-pay for SmartStudent Metro passes at \$22 per month (if the families pay, the schools should reimburse families) or you can pre-pay for these passes for your D.C. K-12 students. Individual private transportation service will not be allowed (e.g. gas or mileage for a personal car). WSF will consider all other transportation methods on a case-by-case basis. If you have a question about a particular transportation method and whether it is allowable, please call WSF at (202) 293-5560. If a student uses public transportation, the family will need to provide you with receipts for payment and you and the family will have to decide if you want this fee to count towards the $\$ 7,500$ cap. 
Hopefully this letter has answered all of your questions about fees. If you have any further questions, please call either me at (202) 293-5560, ext. 16 or Ed Greenberger at ext. 15. We want to thank you again for all your hard work and patience. We are about to embark on a historic journey and it could not have happened without you.

Sincerely,

Ruth Bollinger

Chief Financial Officer

Washington Scholarship Fund 


\section{ABOUT THE AUTHORS}

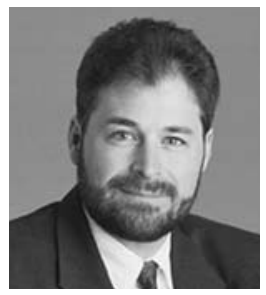

Principal Investigator Dr. Patrick J. Wolf is Associate Professor of Public Policy at Georgetown University. He also is Principal Investigator of the DC Opportunity Scholarship Program impact evaluation, supported by the U.S. Department of Education, through a sub-contract with Westat. Dr. Wolf has authored, co-authored, or co-edited two books and more than twenty articles and book chapters on school choice, special education, public management, and campaign finance. He was a member of the Gates-Brookings National Working Commission on Choice in K-12 Education and helped draft its final report. Wolf has designed, managed, and reported about education reform studies that employ a wide variety of research methods including experimental, quasi-experimental, meta-analytical, and qualitative investigation techniques. He received his B.A. in Political Science and Philosophy at the University of St. Thomas in 1987 and his Ph.D. in Political Science from Harvard University in 1995.

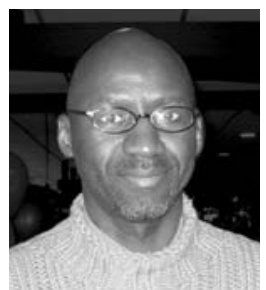

Senior Research Associate Dr. Thomas Stewart is a Managing Partner with Symphonic Strategies. In 1994 he became the first graduate of the University of the District of Columbia to receive a Ph.D. from Harvard University. His research, consulting and other professional activities have focused on improving the quality of life for under-resourced children and families. He has held senior executive or board member positions with the Black Alliance for Educational Options, Edison Schools, LearnNow, the National Black Graduate Student Association, Parents International, and the SEED Public Charter School.

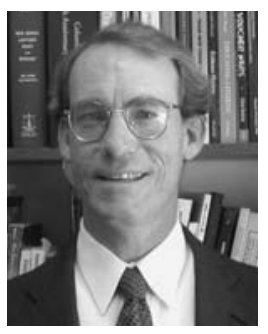

Administrator Stephen Q. Cornman, Esq. is a public policy specialist with ten years of government experience as Chief of Policy and Planning for the largest County in New Jersey, Deputy Director of the Essex County Improvement Authority, and Policy/Budget Assistant to former Borough President Fernando Ferrer in New York City. He is the author of Urban Policy in Essex County, NJ: Improving Education, Economic Development and Quality of Life (1998). He practiced law for eight years and is an active member of the District of Columbia Bar. He is a Columbia University M.P.A., Thomas Jefferson School of Law J.D., and a candidate for a Ph.D. at Columbia University.

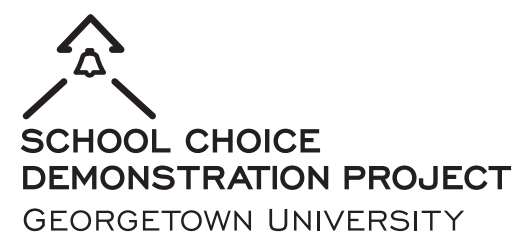

3300 Whitehaven Street, NW, 5th Floor, Box 571444 Washington, DC 20057-1485

www.georgetown.edu/research/scdp

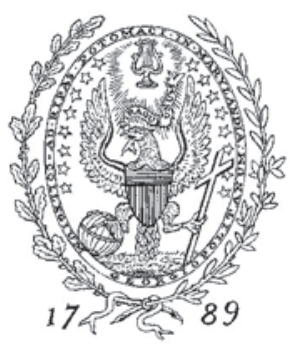

(202) 687-6323 


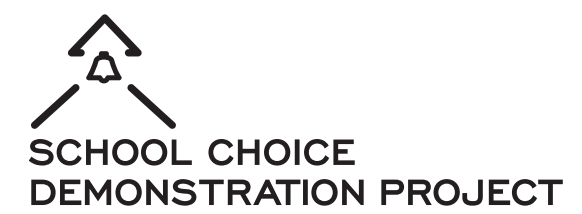

GEORGETOWN UNIVERSITY

Public Policy Institute

3300 Whitehaven Street, NW, 5th Floor, Box 571444

Washington, DC 20057-1485

www.georgetown.edu/research/scdp

(202) 687-6323

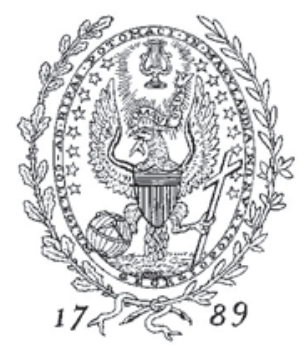

Copyright (c) 2005 